\title{
The coordination between train traffic controllers and train drivers: a distributed cognition perspective on railway
}

\author{
Rebecca Andreasson ${ }^{1}$ (D) Anders A. Jansson ${ }^{1}$ (D) . Jessica Lindblom ${ }^{2}$ (D)
}

Received: 6 April 2018 / Accepted: 25 July 2018 / Published online: 2 August 2018

(c) The Author(s) 2018

\begin{abstract}
Although there has long been a call for a holistic systems perspective to better understand real work in the complex domain of railway traffic, prior research has not strongly emphasised the socio-technical perspective. In operational railway traffic, the successful planning and execution of the traffic are the product of the socio-technical system comprised by both train drivers and traffic controllers. This paper presents a study inspired by cognitive ethnography with the aim to characterise the coordinating activities that are conducted by train traffic controllers and train drivers in the work practices of the sociotechnical system of Swedish railway. The theoretical framework of distributed cognition (DCog) is used as a conceptual and analytical tool to make sense of the complex railway domain and the best practices as they are developed and performed "in the wild". The analysis reveals a pattern of collaboration and coordination of actions among the workers and we introduce the concept of enacted actionable practices as a key concern for understanding how a successfully executed railway traffic emerges as a property of the socio-technical system. The implications for future railway research are briefly discussed.
\end{abstract}

Keywords Distributed cognition $\cdot$ DCog $\cdot$ Railway $\cdot$ Rail human factors

\section{Introduction}

Research relating to aspects of human factors in the railway domain is a relatively understudied area of inquiry, especially if compared to aviation and road traffic. It is, however, a highly dynamic domain with a plenitude of research challenges yet to be investigated. Due to the ever-increasing traffic demands, the transportation domain in large is pressured to increase the capacity and handle a greater number of transportations while maintaining high levels of safety and efficiency. This has led to frequent changes and updates in technical equipment as well as increased levels of automation. These changes are often accompanied by changes to the organisation of work and work processes (Woods and Branlat 2010).

When it comes to human-technology interaction, much attention has been paid to the technology and too little to the "human capital", i.e., the humans using the technology

\footnotetext{
Rebecca Andreasson

rebecca.andreasson@it.uu.se

Uppsala University, Box 337, 75105 Uppsala, Sweden

University of Skövde, Box 408, 54128 Skövde, Sweden
}

(e.g., Norman 1993; Sandblad et al. 2003). Three historical reasons for that situation, among others, are the following. First, the user in human-technology interaction has generally been viewed as factors, a passive element of the information-processing. This has lately started to shift to a view of the users as human actors with their own agendas (Andreasson et al. 2015; Bannon 1991, 2011). Second, much emphasis has been focused on the technological aspects of human-technology interaction; technology was considered as the hard component and humans' interpretation of the technology, tools, and cognitive artefacts was considered as the easy part (Norman 1993; Rogers 2012). Third, more easily computerised activities are already automated, and the time has arrived when the more demanding cognitive tasks have to be dealt with in automation (Sandblad et al. 2003). These lines of reasoning also apply to the railway domain, due to the increasing development of information and communications' technology that should support the work practices to enhance safety and efficiency.

Prior railway research is multifaceted and conducted across scientific disciplines, for example, focusing on improvements of the mobility and transport networks, the development of lighter trains with higher performance possibilities, and aspects related to the business, economics, 
and social parts of rail transport (Wilson et al. 2007b). Much of the research relating to the planning and execution of railway traffic belongs to the field of human factors and ergonomics (HF\&E), which has long played an important role when it comes to optimising human performance in a variety of complex work domains. Savioja et al. (2014) stress that the common practice in safety-critical domains is to focus on performance-related issues, which are highly influenced by HF\&E research. Due to the prevailing orientation towards HF\&E, railway research runs the risk of not considering the modern understandings of human cognition and technology-mediated activity, as situated action (Suchman 1987), embodiment (Lindblom 2015), and distributed cognition (Hutchins 1995a), in which humans are considered as meaning-making actors (not factors) in a socio-cultural and material context. Work carried out within complex settings are often by their nature ill-defined and challenging to study in laboratory settings (Wilson et al. 2003) or in simulators (Farrington-Darby et al. 2006). It is, therefore, essential that work within complex socio-technical systems are studied as it unfolds naturally. Hence, there is a need for field studies that take the social variables, the complexity of the environment, and the effects these have on behaviour and performance into account (Farrington-Darby et al. 2006). Wilson and Norris (2005) especially emphasise the need for field research with the aim to understand distributed groups working with multiple interfaces. To increase the understanding of how activities are coordinated and executed in operational railway traffic from a systems perspective, the unit of analysis needs to be broadened beyond the individual and even beyond the separate work roles. For this purpose, we suggest that the theoretical framework of distributed cognition (DCog) (Hutchins 1995a) is a convenient way forward. With this view on railway traffic as a complex socio-technical system, the need to study both cognitive and social activities in practice becomes evident, and also the need for incorporation of external resources that are available to execute operational railway traffic and coordination in practice. The DCog framework (Hutchins 1995a, b) is one of the most prominent research-in-the-wild (RITW) approaches that were introduced nearly three decades ago (Rogers 2012; Rogers and Marshall 2017). Hutchins (1995a) started to write about cognition being-in-the-wild, stressing that, e.g., communication and problem solving when observed as it unfolds in practice, is distributed and embodied in the social and material sphere and situated in the moment. This means that the researcher gets first-hand experience of the current workspace. A key concern in RITW studies is to reveal what actually happens in the real world, how do humans act and behave in situ, what kind of material and social resources do they use, when, and in what ways?

In this paper, we apply the DCog perspective to the structure of cognitive activity in the distributed socio-cultural and technical system of railway traffic. More specifically, the research problem addressed in this study is the limited understanding of how activities are coordinated and executed in operational railway traffic. Accordingly, the aim of this study is to investigate and analyse the coordination activities in play in operational railway traffic, conducted by train traffic controllers and train drivers working within the socio-technical system of Swedish railway from a DCog perspective.

We report on a workplace study (c.f. Luff et al. 2000), inspired by cognitive ethnography (Hollan et al. 2000), aiming at an increased understanding of how system resources are organised and used in operational railway traffic by traffic controllers and train drivers in their task to accomplish a successful traffic flow, safe, and comfortable rides for the passengers with infrequent delays and optimised energy consumption. Cognitive ethnography is rooted in traditional ethnography, but differs from it in a fundamental way. Whereas traditional ethnography is concerned with the meanings that members of a cultural group create, cognitive ethnography is concerned with how members create those meanings and applies the DCog lens to describe this process (Hollan et al 2000; Williams 2006). Hence, cognitive ethnography is a tool for studying situated activity, and it is particularly apt for investigating the nature of real-world contexts by conducting "research in the wild" from a DCog perspective. The real-world context in this study is the railway. The primary unit of analysis is the cognitive system of Swedish railway traffic, which is comprised by several actors, tools, and cognitive artefacts-i.e., artificial things that aid or enhance the human's cognitive abilities such as, for example, calendars or computers (Norman 1991). ${ }^{1}$ Together with strategies, rules, and understandings, these guide the interactions in the structure of the shared and distributed workspace. In the context of railway traffic, we consider the functional system to include train traffic controllers and train drivers as well as the multiple tools and cognitive artefacts they use to support and coordinate their work.

By studying successful work (Hollnagel 2009), it is possible to understand the skills of the railway workforce and how these skills and experiences can be integrated with new technical and organisational systems, which Wilson and Norris (2005) stress as a major requirement for the future of railway traffic. It is our belief that an RITW study with DCog as its theoretical framework will provide an increased understanding and a systems perspective of how operational railway traffic is successfully performed "in the wild".

\footnotetext{
${ }^{1}$ In this paper, we do not explicitly distinguish between tools and artefacts, but recommend the interested reader to see the work by Susi (2006) regarding different characterisations of tools and artefacts.
} 
The remainder of this paper is structured as follows: Sect. 2 provides a description of prior railway research mostly carried out within $\mathrm{HF} \& \mathrm{E}$, focusing on train traffic control and train driving to motivate and frame the work presented in this paper. This section also motivates the need for a systems perspective in railway research in large, and introduces the theoretical framework of DCog. Subsequent sections outline the chosen empirical approach and the findings, including the introduction of the new concept of enacted actionable practices as a theoretical contribution to the DCog community. The paper ends with a discussion, some conclusions and a list of implications for future railway research.

\section{Background}

Section 2 first introduces an overview of general characteristics of railway research. The categorisation of the research presented is neither completely fixed nor does it provide an exhaustive review of the literature. The purpose of this review is rather to illustrate the diversity to be found in the scientific literature on railway traffic and to display the complexity of this safety-critical environment with emphasis on the two work roles: train driver and train traffic controller. This leads to an argumentation concerning the role a systems' perspective may play in railway research. Finally, Sect. 2 ends with a description of the theoretical framework of DCog.

\subsection{Railway research}

For many years, the railway was a slowly evolving business, and despite a few disruptions and accidents, things appeared to run without difficulties. In accordance with this, we have seen a general lack of interest for research on issues relating to rail human factors, especially when compared to other transport industries such as aviation and road transport. However, since the mid-1990s, this has changed and the interest in railway operations has never been greater amongst the public, governments, media, academics, and practitioners (Wilson and Norris 2006). This change was highly influenced by the Chief Engineer of Network Rail who in an opening talk at the First European Conference on Rail Human Factors highlighted a change in public and government perceptions along with technical developments, and the influences this brought to an industry, where nothing much had changed for 150 years (McNaughton 2003, in Wilson and Norris 2006). He described the railway industry as a complex engineering system with the human at the centre and elucidated that HF\&E research could greatly contribute to this domain.
Looking back at the last 30 years, we see an increased number of passengers, more trains running in the same envelope of time, and constant changes and developments in the technology used for identifying the locations of the trains on the tracks and for communication between train and control functions. This also causes difficulties when it comes to creating and maintaining a timetable and the infrastructure requires more frequent maintenance, inspections, and repairs.

Given the many challenges of the railway domain, the contributions of railway research cover a broad range of different aspects regarding the realisation and maintenance of a safe, reliable, and efficient use of the capacity of the railway. The investigated aspects include human and organisational issues on the railway, driving behaviour and design of locomotives, signalling and control, passengers and security issues, maintenance and engineering work, and much more (see Dadashi et al. 2013; Wilson et al. 2012 for an overview).

There are complex underlying structures, separate organisations, and roles with different tasks involved in the many phases of railway traffic. Some processes are active ahead of time, such as timetabling and resource planning, while others are operational and related to the actual operation of the traffic. This paper focuses on the operational railway traffic and the work processes with immediate connection to the actual train operation. This work could be said to involve several work roles, but in this paper, we focus on the roles of train traffic controller and train driver. Thus, other work roles and work processes (e.g. different types of maintenance work and customer information) fall out of the scope of this paper.

\subsubsection{Research on train traffic control}

Train traffic controllers (sometimes also called traffic planners, train dispatchers or signallers) are engaged in a remote control process, monitoring and manually executing actions that control train paths, points, and signals. When necessary, the traffic controller reschedules the traffic plan with respect to the current traffic situation. Prior research when it comes to train traffic control has paid attention to the introduction and use of automation. Electro-mechanical technologies enable remote control and running of the railway services, and the trend to centralize traffic control enables increased support of different kinds of automation to regulate train settings. One practical issue with railway automation is that the traffic controller rarely has knowledge about how the automation is selecting routes and, therefore, tends to distrust the automation (Balfe et al. 2012; Golightly et al. 2013). In fact, when the timetable moves into an unpredicted state and the traffic controller needs to solve traffic conflicts and make time critical decisions, it has been shown that the controller often turns off the automatic functions (Golightly 
et al. 2013). This should be considered as an example of the "irony of automation" (cf. Bainbridge 1983), indicating that the potential support from automatic functions often is unwanted and turned off in situations when they would be needed the most.

One impending risk with increased automation and the lack of transparency is that the traffic controller's situation awareness (SA) for the ongoing traffic situation might be negatively affected if they do not understand what the automatic system is doing. Situation awareness is a theoretical concept that originates from human factors studies on air traffic control and aviation, and it refers to the gathering and understanding of information (Endsley 1995). The concept is debated, but well established in safety-critical domains by both researchers and practitioners (e.g. Millot 2015; Salmon et al. 2008). However, it has been argued that SA is more about coordinating activities between team members and social and material resources than something an individual can possess (Artman and Garbis 1998; Hazlehurst et al. 2007). A similar line of thought is presented by Golightly et al. (2012) in a study of how well-experienced train traffic controllers can answer questions related to current and future states of elements in a simulated traffic situation. The authors concluded that "information is shared between the 'head' and the 'world' and that signallers may leave information in the display until it is needed" (Golightly et al. 2012, p. 368). They also suggest that the notion of constantly "maintaining SA" is likely to be about strategies for acquiring and using information on a timely basis (SA as a "process") rather than maintaining an internal representation of the system's status (Golightly et al. 2012).

Another aspect of automation that has received interest in railway research is the inclusion of decision support for operational planning and control. The issue has been addressed from different perspectives, for example, with the use of algorithms to calculate an optimal solution for how to recover from disturbances (Corman and Meng 2013), and the development of decision-support systems to help the controllers identifies and solves traffic conflicts (Kauppi et al. 2006). The latter example is a human-centred perspective of decision support and the authors describe how the traffic controllers lack adequate support to perform efficient traffic control during severe disturbances. They identify several problems of today's way of working in relation with the design of the traffic control systems used. These problems include: lack of overview, fragmented information from a handful separate information systems, difficulty to obtain necessary information, lack of precision in data (e.g., regarding the exact position and speed of a train), and sometimes outdated information. The dynamic nature of railway traffic results in frequent changes and improvements of the traffic plan and Kauppi et al. (2006) propose a new decisionsupport system with a dynamic planning view that helps the controller identify and handle disturbances and conflicts via direct manipulation of a time-distance graph in the interface. The authors argue that this solution provides the necessary support for the controllers to reach a continuous awareness of the dynamic development of the traffic process.

Yet another relevant aspect when it comes to prior research in relation with the role of being a train traffic controller concerns the psycho-social factors of experiences of stress, workload, and fatigue. As a traffic controller, you may perceive pressure of making correct, timely decisions and to take effective actions, which has resulted in the development and evaluation of methods and tools for assessing the mental workload imposed on train traffic controllers (e.g. Pretorius 2012; Shanahan et al. 2012).

\subsubsection{Research on train driving}

When it comes to train driving, prior research has focused on, for example, the work environment, and when studying the drivers' use of information and how this affects driver behaviour, two different driving styles were identified: reactive or proactive driving (Jansson et al. 2005). It was also revealed that the drivers experienced a lack of information and that they considered it highly challenging to obtain relevant information, which naturally makes it problematic to adopt a proactive driving style. In fact, Jansson et al. (2005, p. 40) concluded that "...the drivers sometimes found themselves driving in an informational vacuum". The drivers needed to use and integrate information from several information channels such as the trackside signals, the route book, and surroundings near the track, and still much relevant information were absent. A later study revealed that the need for information differs along the route (Jansson et al. 2006). Especially, three different phases were identified: (1) on the route; (2) approaching a station; and (3) leaving a station. On the route, the driver is focusing on the speed limit and adjusting the speed as they go along to meet the timetable. When approaching a station, the driver's attention shifts towards the surrounding environment, e.g., weather conditions might affect the braking capacity of the train, people on the platform, trains nearby, or signals expected to show clear through the points. Finally, when leaving a station, the driver wants to get away as quickly as possible to keep up with the timetable (Jansson et al. 2006).

Another aspect related to the activity of leaving the station on time is the behaviour of the passengers. The drivers' possibility to communicate with others is highly limited and they are often unable to see all that is happening on the platforms. Based on these circumstances, it is difficult for the drivers to know when the exchange of passengers entering and exiting the carriages is finished and when they can close the doors and leave the platform. Therefore, when the platform is crowded, the drivers have to encourage passengers 
to behave in particular ways, and with the few resources available. Heath et al. (1999) describe how train drivers in the London underground have developed implicit strategies to communicate with the people on the platforms, for example, using the warning sound of closing doors to affect the passengers conduct. Any accustomed traveller knows what that sounds mean, and on hearing the sound, some people will make a final attempt to get on board the carriage, while others will step away from the train. The sound occurs just as the doors are about to begin to close, which gives the drivers the opportunity to press the button that (re)opens the doors. The authors describe how the drivers sometimes repeat this action several times in an attempt to engender particular actions and activities of the passengers.

Working in shifts, often with long and uncertain work hours, makes sleep loss and fatigue a serious issue for train drivers. Fatigue has been shown to affect alertness and psychomotor vigilance. In addition, driving parameters are affected, for example, with increased fuel use, less use of throttle and dynamic brake, and more heavy brake and maximum speed violations. Clearly, fatigued driving becomes less well-planned and may cause reduced efficiency (increased fuel use and economic cost) and reduced safety through braking and speed violations (Dorrian et al. 2007a, b).

Keeping track of the speed, taking note of the signals along the railroad tracks, stopping at the right station within a strict timetable, taking note of information coming from the surroundings (for example, wildlife running close to the tracks) and operating the train in an energy efficient and economical way (so-called eco-driving) are examples of activities between which the driver must divide his attention. Automatic train protection systems (ATP) support the drivers to safely operate the train; however, until recently, the drivers had minimal or non-existent support for handling the different and constantly varying sources of information (Albrecht 2013). Drivers were often running close to the speed limit and when coming too close to a preceding train or when they reached meeting points too early, they had to decrease speed or even go to full stop. This resulted in high operating and energy costs, which in turn initiated the development of the Driver Advisory System (DAS) to support economic driving (Tschirner et al. 2013). A DAS provides real-time information regarding the position of trains and gives advice on how to optimise traffic flow and energy efficiency by constantly suggesting updated speed limits with respect to time and distance to the next station (Yang et al. 2013). This enables the drivers to adjust their driving behaviour to the overall traffic situation, which leads to increased quality of railway traffic in terms of safety, punctuality, comfort for the passengers, energy consumption etc. (Tschirner et al. 2013). However, it has been suggested that the increase in displayed information may cause information overload
(Kecklund et al. 2011) and a "heads up, heads down" type of driving, indicating that the drivers are forced to constantly shift their visual attention from monitoring the outside of the train to attend to information presented inside the locomotive (Naghiyev et al. 2014).

\subsection{Railway research in need of a systems perspective}

Despite a substantial body of research related to the planning and execution of railway traffic, few studies have attempted to focus on understanding the interactions taking place between the central roles (Wilson 2000, 2014) and how they enable successful work performance. This is addressed by Golightly et al. (2013) who put forward roles and communication as examples of aspects important to better understand in order for the research to keep up with the dynamic structures of railway traffic. When it comes to roles, Golightly and colleagues describe that it is important to map out the structure and relations between different roles and to understand the work processes for each role. In addition, communication patterns and channels between different work roles, e.g., train drivers, railway undertakers etc., need to be further investigated and understood. This is not the first time that the need for a systems perspective has been put forward as essential for the future of railway research (e.g. Wilson and Norris 2005). However, as can be seen in the previous sections, the attempts made in this direction have not fully managed to expand the unit of analysis to include more than one of the central actors. Furthermore, when looking at the literature, the research rarely focuses on interactive aspects such as communication and information sharing activities and they rarely consider that the different work roles are part of the same distributed socio-technical system and dependent on each other in order for the railway traffic to run according to plan.

One of the main advocates for adopting a systemic view in railway research (as well as in HF\&E in general) was the late John Wilson who argued for humans to be studied and understood within their own context of work (Wilson 2000, 2014). In domains, such as railway, where it is common with distributed groups working with multiple interfaces and sometimes even towards different goals, the need for a holistic systems perspective could be argued to be even larger (Wilson and Norris 2005). Wilson et al. (2007a) stressed the need to study distributed cognition in railway work, but failed to acknowledge Hutchins's (1995a) already existing theoretical framework of distributed cognition (DCog). Based on this, the current study covers the operational organisation of train traffic control and train driving, with the aim to characterise the coordination activities conducted by train traffic controllers and train drivers working within the socio-technical system of Swedish railway from 
Fig. 1 Traditional cognitive science perspective is depicted to the left, suggesting that the unit of analysis is restricted to the mind of the individual. From a DCog perspective (depicted to the right), the unit of analysis is distributed across people and artefacts within the cognitive system, and cognitive processes are the result of the interactions between these entities of the system (Lindblom and Thorvald 2017, p. 65)

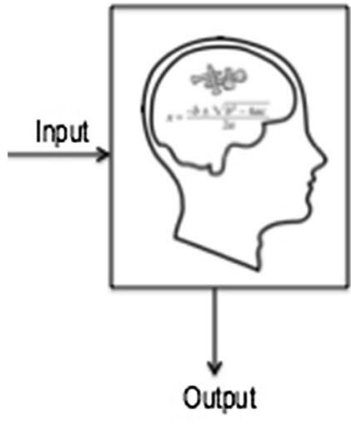

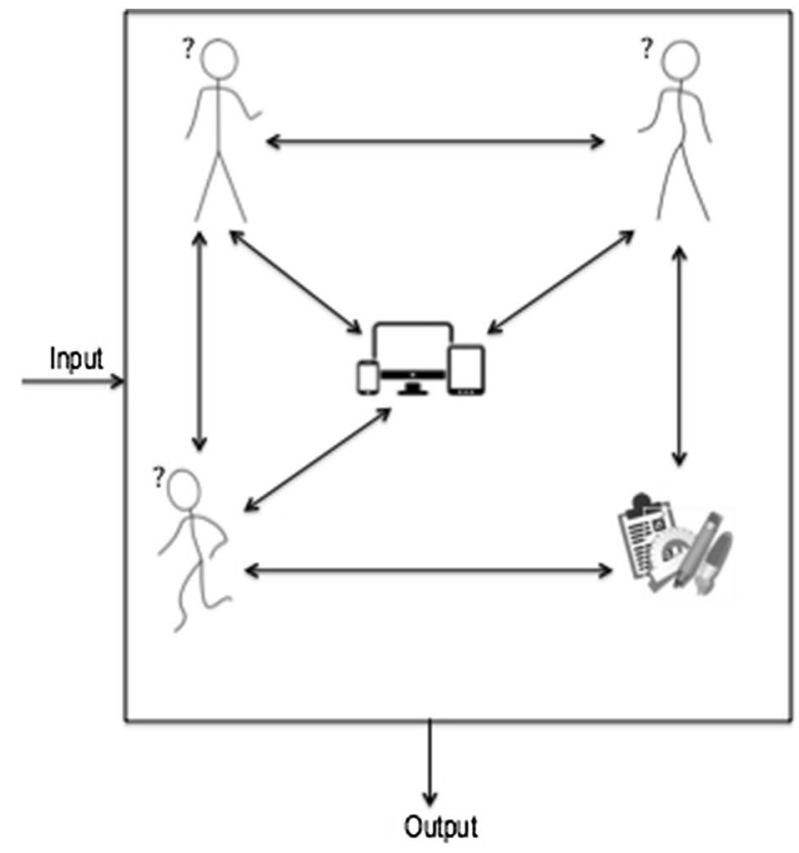

a distributed cognition (DCog) perspective. The Swedish operational railway is well developed both technically and when it comes to the organisation of work processes for integration of collaboration between drivers and traffic controllers. Therefore, we believe that highlighting the current human factors challenges in the context of Swedish railway will contribute also to international railway and provide insights on how to support the individual workers in the distributed work of creating a successful coordination between traffic controllers and train drivers.

\subsection{The theoretical framework of DCog}

The most common view in traditional cognitive science is that human cognition is internal to the individual. This means that humans act on internal representations of the world, i.e., mental representations that represent something else. However, in response to these individual models for theories of human cognition, Hutchins (1995a, b) introduced the theoretical framework of distributed cognition (DCog) and proposed that cognition should be studied "in the wild" as it naturally unfolds. From a DCog perspective, the unit of analysis is broadened and human cognition is considered to go well beyond the boundary of the individual organism and is instead fundamentally distributed in the socio-cultural and technical environment that the human inhabits (see Fig. 1).

In accordance with the system perspective, DCog discards the idea that the human mind and environment can be separated and suggest that cognition is not contained inside the mind of the individual, but should instead be considered a cultural process. Hence, DCog views cognition as distributed in a complex socio-cultural and technical environment and studies cognition in the form of the creation of representational states, and the transformation and propagation of these within the socio-technical system (Hutchins 1995a). When cognition is considered an emergent phenomenon resulting from the interactions between different entities in the brain, body, and the social and material environment, cognition is emphasised as a cultural process based on interactions between different entities that together create a whole that is more than the sum of the individual parts. Accordingly, socio-technical environments, which include people and their everyday actions, should be viewed as a reservoir of resources for cognitive processes such as learning, decision-making, problem solving and reasoning (Hollan et al. 2000). This provides one of the main benefits with having DCog as the theoretical perspective, namely, the possibility to vary between different levels of granularity and move between levels of analysis (Rogers 2012). Hence, the boundary of what is analysed as the socio-technical system can be anything from the individual level to the organisational one, and beyond. From the combined effort of the individuals, an emergent phenomenon arises which allows the system to be self-organising and to reach goals that the sum of the individual efforts would not have been able to achieve.

Two core principles make the DCog framework differ from the traditional cognitive science models: The first principle concerns the boundaries of the unit of analysis for cognition. As mentioned above, DCog defines this by the functional relationship between the different entities of the cognitive system. The second principle concerns the range of processes considered to be of cognitive nature. From a DCog perspective, cognitive processes are viewed as 
interaction between internal processes and manipulation of external objects as well as the propagation of representations across the system's entities (Hollan et al. 2000). When these principles are applied to the observation of human activity in situ, it is possible to observe three kinds of distributed cognitive processes. These are: (1) across the member of a social group, (2) between internal structures (e.g. decisionmaking, memory) and external structures (e.g. material artefacts, technical systems, social environment), and (3) distributed over time (Hollan et al. 2000, p. 176).

Since its inception in the mid-1990s, the DCog approach has gained increased interest and been used as an analytic tool for better understanding the interactions between humans and technology in various settings and contexts (Rogers 2012). Since it is fundamental in DCog to focus on cognitive artefacts and the way in which information is propagated and transformed within the socio-technical system, this is a natural development. It is, therefore, common in DCog research to provide detailed analyses of tools and cognitive artefacts and the way they function as coordination mechanisms between external and internal structures. The study of these material structures, i.e., tools and tool use, reveal properties of cognitive structures and makes them visible "beyond the skull" (Hutchins 1995a).

Cognitive artefacts and tools can also serve as mediators in social interaction. It is, therefore, important to recognise how information is transformed when mediated through tools and artefacts (e.g. Clark 1997; Hutchins 1995a, b). The use of strategies such as taking advantage of external structures to coordinate cognitive activity might be considered a complementary way of explaining intelligent action. Both internal and external structures are central to the unit of analysis in DCog and Hollan et al. (2000) argue that representations not only refer to something other than themselves, but are also manipulated as physical properties. This means that humans shift from attending to the representation, to attending to the thing that is being represented. Hutchins's classical example of this is the navigational chart used for offloading cognitive efforts (e.g. memory, decisionmaking) to the environment. When studying cognition with this extended unit of analysis, it is clear that the functional cognitive system has cognitive properties that cannot be limited to the cognitive abilities of the individual(s). In a general sense, the human brain and body plus these external resources result in the "mind" and cognition is distributed across the agent, the "in the wild" situation and its resources.

DCog has received some critique regarding the framework's view of the nature of cognitive phenomena and its utility as an analytic tool (Rogers 2012). Nardi (1996), among others, has criticised the need for extensive fieldwork to reach a proper analysis of the cognitive work in a certain setting, and Rogers (2012) as well as Berndt et al. (2014), pointed out the skill necessary for a DCog analyst to be able to move between the different levels of analysis in the accomplishment of a proper DCog analysis. Also the lack of interlinked concepts to be used to identify specific aspects from the collected data (Nardi 1996) and the few theoretical constructs (except at the basic level of representational states) (Halverson 2002) has been put forward as challenges for the DCog analyst. Considering the challenges associated with the application of DCog, the theoretical framework should not be considered a "quick and dirty" approach.

Although Hutchins himself developed cognitive ethnography as a tool for collecting data that could be analysed via the DCog lens (Hollan et al 2000; Williams 2006), some researchers still argue that DCog lacks a proper tool or method for proper data collection. Consequently, DCog has been used as a base for developing several methods, including the Resources model (Wright et al. 2000), DIB method (Galliers et al. 2007), CASADEMA (Nilsson et al. 2012) and DiCoT (Blandford and Furniss 2005). Although these methods have their foundation in DCog, some aspects that are of importance for a detailed DCog analysis are omitted and the methods sometimes seem oversimplified (Sellberg and Lindblom 2014). One of these issues regards the changes between representational formats and the lack of a proper notation for these changes although they often occur between humans, tools, and cognitive artefacts, and, therefore, are of high relevance in DCog. Some initial attempts to overcome this gap have been developed in a manufacturing domain (Lindblom and Gündert 2017).

Substantial research in a variety of domains has been done with DCog as the theoretical perspective. This includes, for example, ship navigation (Hutchins 1995a), cockpit work (Hutchins 1995b), human-computer interaction (e.g. Hollan et al. 2000; Rogers and Ellis 1994), heart surgery teams (Hazlehurst et al. 2007), manufacturing (Andreasson et al. 2017a, b; Lindblom and Thorvald 2017), information visualisation (Liu et al. 2008), and nuclear power plants (Mumaw et al. 2000). DCog could serve as an appropriate theoretical lens for investigating and analysing the complex work activities in operational railway traffic and provide a portrayal of how people, environment and tools are coupled and related to each other. However, to the best of our knowledge, it seems that DCog has not previously been applied to the railway domain despite some initial steps by Andreasson et al. (2018).

\section{Method}

This section presents a workplace study with cognitive ethnography as its tool of inquiry. The study is performed in the Swedish railway setting with the overarching goal to understand the coordination activities conducted by train traffic controllers and train drivers working within the 
socio-technical system of Swedish railway from a DCog perspective. The section starts with a description of the research approach and continues with an introduction to the research setting.

\subsection{Research approach}

This RITW study was designed as a workplace study with DCog as its theoretical lens, exploring the work activities of traffic controllers and train drivers in Sweden by means of ethnographic fieldwork (cf. Luff et al. 2000). Workplace studies aim at describing how people accomplish various tasks in the wild and have been described as a prominent method for addressing the interactional organisation of a workplace and the ways tools and technologies are used to support work tasks and collaborations (Heath et al. 2000; Luff et al. 2000). Through first-hand experiences, observations and analysis of daily work activities and practices, a workplace study offers a holistic understanding of work experiences by being concerned with issues beyond the individual tasks (Szymanski and Whalen 2011). The approach used was ethnographic by nature, because it relies on the naturalistic field study of work practices. This entails studying patterns, constructions, and configurations of work practices, as well as the social, cultural, and historical environments, where the work is accomplished. The approach is also cognitive, because we collect data that allowed an understanding of representational states and their effects upon work as it unfolds in situ. Examples of theoretical approaches available for studies of practical actions in the workplace are activity theory (Engeström 2000) and situated actions (Suchman 1987). However, none of these approaches analyses the cognitive aspects of work to the same extent as the paradigm of DCog (Hutchins 1995a, b) does. In fact, DCog and Hutchins's (1995a) study of ship navigation has been described as one of the most illuminating and influential workplace studies done so far (Heath et al. 2000). For the theoretical framework of DCog, both Hutchins (1995a) and Hollan et al. (2000) develop and present cognitive ethnography as a tool for doing a DCog analysis. As such, cognitive ethnography is an extension of ethnography that investigates the functional properties of distributed cognition in socio-technical and cultural systems. This tool entails to have an interest in the individual but with added focus on material and social constructs when it comes to how meaning is developed within the system (Hollan et al. 2000). It should be noted that cognitive ethnography is not a specific technique or method for analysis; rather it is a collection of data techniques such as interviews and observations. Williams (2006, p. 838) describes that "Cognitive ethnography employs traditional ethnographic methods to build knowledge of a community of practice and then applies this knowledge to the microlevel analysis of specific episodes of activity. The principal aim of cognitive ethnography is to reveal how cognitive activities are accomplished in real-world settings". While traditional ethnography describes knowledge, cognitive ethnography describes how knowledge is constructed and used (Williams 2006). Accordingly, cognitive ethnography creates the "corpus" of observed phenomena that DCog then aims at explaining, and as a method of inquiry, cognitive ethnography has a key role to play with its aim to reveal how cognitive processes unfold in real-world settings.

The research design of a workplace study with DCog as its theoretical lens was considered to meet the methodological challenges of this study in several ways. Firstly, cognitive ethnography, in accordance with DCog (Hollan et al. 2000), is useful to gain knowledge about the railway domain in general and the cognitive work of operational railway traffic in particular. Secondly, DCog allows the researchers to move continuously between different levels of granularity and the boundaries of what is analysed as the socio-cultural and technical system can vary and be anything from the individual level to the organisational one, and beyond (Rogers 2012).

The first author conducted ethnographic fieldwork over a period of 1.5 years in both settings of train traffic control and train driving. In total, more than $100 \mathrm{~h}$ of observations of these work roles were performed via first-hand experiences in the natural work settings. All participants (a total of 28: 17 traffic controllers and 11 train drivers) had at least 4 years of experience from working as traffic controllers or train drivers and a majority of them had more than 10 years of experience. In total, there were 17 observation sessions, each lasting from a half to a full working day, i.e., $4-8 \mathrm{~h}$ per session, and in line with the focus of cognitive ethnography, involved detailed inspections of the traffic controllers and the train drivers everyday work activities, observing what and how tasks were being carried out. From the traffic control setting, the researcher was allowed to co-listen to incoming calls, but it should be noted that this was not possible from the train driving setting. During all overt observations, notes were taken that were later elaborated as comprehensive field notes. This reflects the inductive process of learning the work processes in traffic control and train driving and it allowed the first author to move from an outsider's perspective on the empirical context to being an observer looking in with a detailed understanding about the work involved in running operational railway traffic. It should also be noted that the second author has extensive prior experience from conducting research in the railway domain.

Participant observations, field notes, informal interviews, and photographs were the prime sources of data collection techniques used in cognitive ethnography, and the use of these various techniques made it possible to capture different dimensions of the same phenomenon. During and after observations, informal conversational 
interviews took place with the participants (Patton 2002). These enabled contextual follow-up questions based on what had been observed and proved to serve as a valuable data source that enhanced the first author's understanding of the complex domain and revealed issues that was not possible to identify by the observations alone. The data collected from the observations and the informal conversational interviews consisted of quotations and descriptions of what had been observed and expressed by the participants. Moreover, interview data were collected by the first author as a basis for more detailed analysis. For this purpose, pairwise interviews with both train drivers and train traffic controllers were conducted and approximately $5 \mathrm{~h}$ of interview recordings were transcribed. The interviews were semi-structured and focused on the participants' work roles, their views on their collaboration and how they coordinated activities between themselves. Some questions focused also on the need of shared information and communication flow for the two work roles. Based on a few guiding questions, contextual follow-up questions emerged during the conversations.

The analysis of field notes and interview data was done continuously as a sense-making effort, aiming at identifying patterns in data without predetermined hypotheses or predictions, as advocated by Braun and Clarke (2006). The focus in the analysis of the collected cognitive ethnographical data was on the identification of coordination activities in operational railway traffic and DCog's theoretical constructs, including coordination mechanisms, mediators, representation formats, information flow, and propagation (Hutchins 1995a), were used as the theoretical lens (cf. Decortis et al. 2000) through which the cognitive work processes were interpreted. The analysis was inspired by a thematic analysis, which includes a strategic process of actively working with the data, simplifying and searching for themes and categories that corresponds to the aim of the study (Braun and Clarke 2006; Patton 2002), which in this case meant categories of coordination activities performed by traffic controllers and train drivers in their everyday work. In the next step of the analysis, episodes were labelled as instances of certain kinds of work activities, and by repeatedly going through the data, it was possible to identify categories of coordinating activities from the material that was central to the operational practice of running the railway traffic. In accordance with the ethnographic nature of DCog, these categories are presented in the form of descriptive episodes below (Sect. 4). Furthermore, the writing process should be considered an analytical tool used to reach a deeper understanding of what had been seen in the organisations; thus, making the reporting of results part of the analysis. This way of working with analysis as part of the writing process is, among others, described by Wolcott (2009).
As described above, DCog's theoretical constructs (Hutchins 1995a) were used as a theoretical perspective during the analysis (cf. Decortis et al. 2000). This involved an emphasis on information flow and coordination of internal and external representations within the socio-cultural and technical system. These constructs were the "filter" through which the distributed, cognitive work processes in the socio-technical domain of operational railway traffic was interpreted. It should be noted that our empirical work has primarily been guided by, and possibly constrained by, the DCog perspective. This theoretical perspective was used in analysing and interpreting what was studied and, accordingly, the constructs of DCog determined what was considered relevant. The identified categories, and selected episodes to illustrate them, that were most related to the aim of the study are described in Sect. 4.

\subsection{Research setting}

The Swedish railway network is approximately 12,000 $\mathrm{km}$ long whereof only $2000 \mathrm{~km}$ are double-track lines (Trafikverket 2015). Not only are trains bound to movements in only one dimension (compared to airplanes, boats, and cars that have a larger freedom of movement), but the excessive distance with single-track lines makes it challenging to arrange a meeting of two trains, except when they are at a station. This adds to the complexity of planning the traffic and makes it difficult to recover from disruptions and delays. In Sweden, train traffic operation consists of one infrastructure manager and approximately 45 private railway undertakings that organise a variety of traffic, ranging from local commuter trains to long-distance freight transportation (Trafikverket 2016). Train traffic control takes place at eight centralised traffic control centres and each of these holds control rooms that are manned $24 / 7$ by traffic controllers responsible for all railway traffic in a specified geographical area.

The most central actors in the execution of this complex net of traffic is the train traffic controller and the train driver. Accordingly, this research took place at train traffic control centres as well as in locomotives belonging to the largest railway undertakings for passenger trains. Out of eight centralised traffic control centres in Sweden, observational data was collected from six of them. These were selected in an attempt to characterise the large variety when it comes to the different centres and their prerequisites for running an efficient railway traffic. Out of the six selected traffic centres, one of them runs the busiest regional track in Europe, while another one is responsible for a remarkably smaller region with a majority of long-distance freight transportations. While the first traffic centre handles mostly passenger trains with high speed and a carefully planned timetable, the latter is a more flexible type of traffic, transporting only 

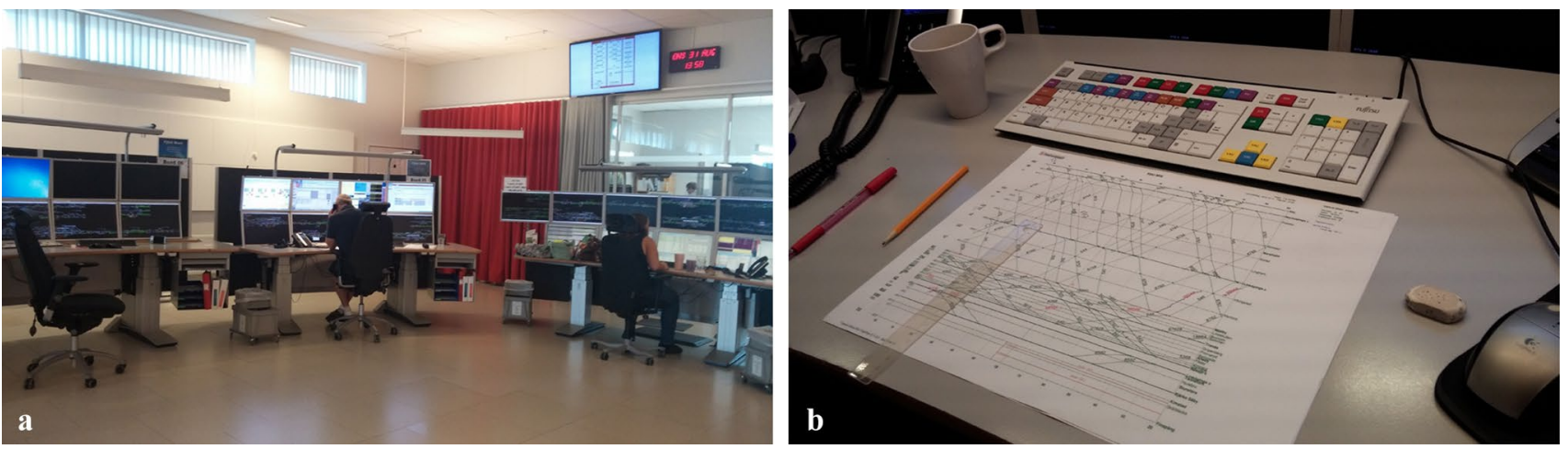

Fig. 2 a To the left, a control room and three workstations for traffic control. b To the right, the main artefacts used for controlling the traffic (the traffic control system, the time-distance graph, and the telephone)

goods, which sometimes can even run completely off the timetable. The third site for data collection is challenged by only single-track lines which often creates difficulties to avoid situations in which a train with low speed limit lies ahead of a fast speed train. The fourth data collection site faces challenges related to busy junctions and large stations functioning as hubs, connecting trains from all over Sweden with thousands of passengers arriving and leaving, and highly frequent departures. The last two of the data collection sites meet a great variety both regarding the type of traffic they encounter and when it comes to the workload. This resulted in sudden shifts between high cognitive load and periods of very low cognitive load.

At each traffic control centre, the traffic controllers work side-by-side located in one large control room (see Fig. 2a). As support for their work, they have three main cognitive artefacts (see Fig. 2b): (1) the traffic control system used to control train paths and to show the status of the infrastructure, i.e., which section of the railroad tracks that are free, occupied by a train, or set for a specific train to soon enter, (2) a printed time-distance graph that shows the traffic plan and onto which all changes should be recorded with the use of a pencil, and (3) a telephone which they mainly use for communicating changes to the train drivers.

It was decided to observe train drivers working at the largest of the railway undertakings. This company transports approximately 130,000 passengers per day with over 1000 departures from all of Sweden (SJ 2018). Train drivers were observed during preparation of the train for departure, while driving the train, and at the end of the shift when handing over the train to another driver. The observations were conducted during whole shifts, which resulted in observations done from inside different types of locomotives, at different times of day and during different types of travels (commuter train and long-distance rides). The locomotives are small and only have room for two people. The driver's environment consists of what can be seen outside the window, i.e., signs and signals, and a number of indicators inside the locomotive to monitor the train (see Fig. 3a, b)

The most important cognitive artefact for the train driver is the Automatic Train Protection safety system (ATP), which uses a beeping sound to indicate when the driver is coming too close to the speed limit. The ATP can also initiate emergency braking if the speed limit is violated or if the train is in danger of passing a stop signal. Another important cognitive artefact is a tablet with the Driver Advisory Systems (DAS). The DAS provides the driver with real-time information necessary for the driver to know the train's current position and advises on a driving behaviour that will support the driver in the task of arriving at the next station in time while driving in an energy efficient manner.

\section{Findings}

This chapter presents the main findings from the workplace study using cognitive ethnography and the findings are presented in the shape of a description of work by traffic controllers and train drivers as it is conducted in the Swedish railway. We begin to explicate the tacit work practices and procedures used by traffic controllers and train drivers to coordinate a disparate collection of tasks and activities. We put forward episodes that were derived from the data analysis as examples of how cognition is distributed within the socio-technical system of railway traffic with emphasis on the intersection between these interdependent roles and their coordination activities. Since DCog provides few theoretical constructs, the findings are largely descriptive and narrative. However, this makes it possible to reveal how cognitive strategies and best practices of traffic control and train driving unfolds in the real-world setting (c.f. Halverson 2002; Rogers 2012; Williams 2006). In the following subsections, selected episodes from our study are presented from a DCog perspective with the aim to portray established 

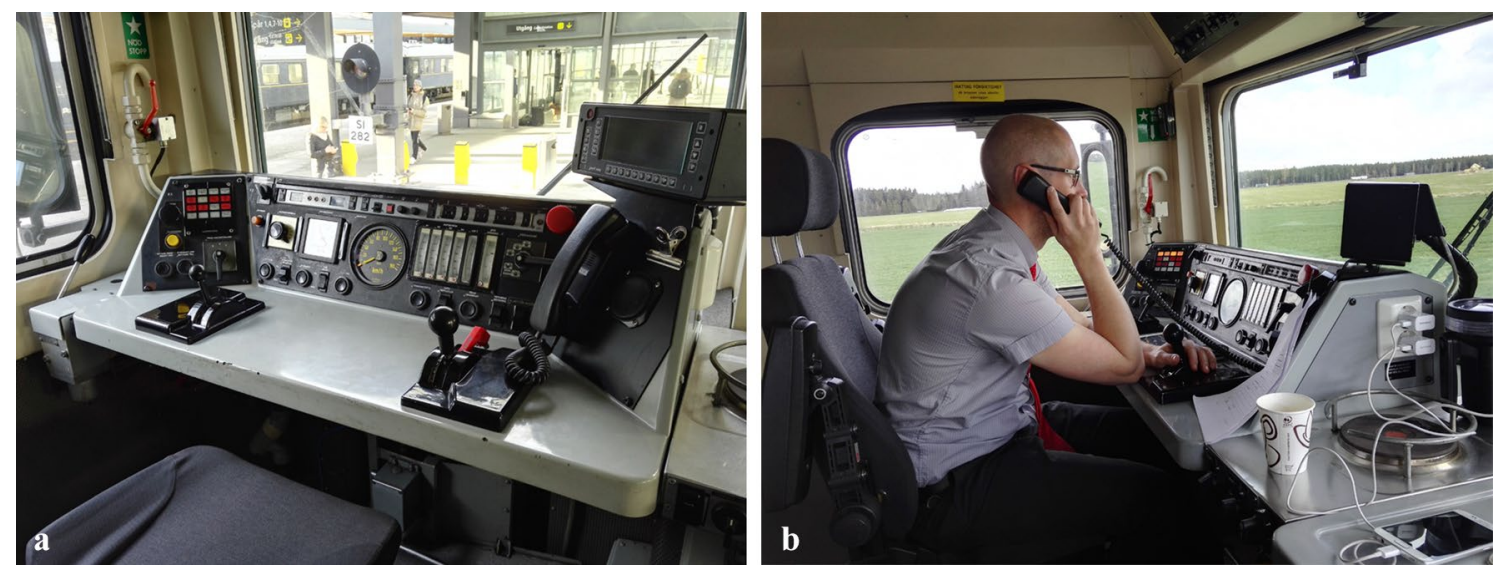

Fig. 3 a To the left, the train driver's workstation in the locomotive. b To the right, the train driver driving the train while talking to the traffic controller on the telephone

work practices and reveal cognitive aspects related to coordination activities developed by the traffic controllers and train drivers in their strive to accomplish a successful railway traffic in practice.

\subsection{Railway traffic in the wild}

The planning process for the railway traffic begins 1 year ahead of actual operation. However, in this paper, the focus lies on the realisation of the traffic plan and the potential replanning that is deemed necessary in the few hours leading up to actual traffic operation to adapt to the ongoing traffic situation. In this work, the two main actors are the train traffic controllers and the train drivers.

The role of being a train traffic controller (sometimes also called traffic planner, train dispatcher, or signaller) comes with varying tasks and responsibilities depending on the historical development of the railway and, therefore, may differ between countries (e.g. Golightly et al. 2013). In Sweden, where this research took place, the train traffic controllers normally take on two different type of activities: one mainly concerns the task of rescheduling the traffic with respect to delays and disruptions, whereas the other is monitoring and manually executing actions that control train paths, points, and signals. The first of these tasks is done as a problemsolving activity and the controllers make decisions in a short period of time to always maintain the traffic within its capacity limits - the slightest delay may end up with a faster train followed by a slower one, throwing the rest of the timetable into chaos: "The most important thing is to make a decision. If you don't act fast, there is a vast risk that you will be handling the same delay from the moment it arises until you go home for the day" 2 (TC6). ${ }^{3}$ To facilitate such fast decisionmaking processes, the work of the traffic controller has to

\footnotetext{
${ }^{2}$ All quotes are translated from Swedish to English.
}

be clearly defined so that he may understand the problems and provide solutions in a quick and efficient manner. In this process, the controllers have access to decision support in the shape of a time-distance graph (see Fig. 4), that displays the traffic plan and supports the controller in the task of planning ahead. The task of monitoring and manually executing actions to control train paths, points, and signals is done in interaction with a digital traffic control system that allows the controller to directly manipulate signals and points, or to set train routes that the automatic functions will execute when appropriate. This exemplifies several instances of coordination between external structures (e.g. the paper-based analogue time-distance graph and the digital traffic control system) and internal (mental) structures in the organisation of information involved in the planning, problem solving, and decision-making done by the traffic controllers in the control room.

The environment of one traffic controller represent a subset of the whole traffic control operation, and subsequently, the individual controller will pass its trains (and sometimes its problems) to another controller. Thus, planning, communication, synchronisation, and coordination are at the core of train traffic control.

As long as nothing unforeseen happens and the traffic follows the already set plan, traffic control is the work of individual workers. However, one of the traffic controllers (TC4) explains that "You are affected by what decisions the others make. There is an ongoing discussion in the room".

\footnotetext{
3 To keep confidentiality, all participants will be referred to as TC (traffic controller) or TD (train driver) followed by an identification number, e.g. TC6 indicates the sixth traffic controller to participate in the study.
} 
Fig. 4 One example of a timedistance graph that shows the traffic plan and onto which the traffic controller draws all changes (with the use of pencil and ruler). Each vertical line represents a train, and the angle corresponds to its speed, while the horizontal lines are train stations

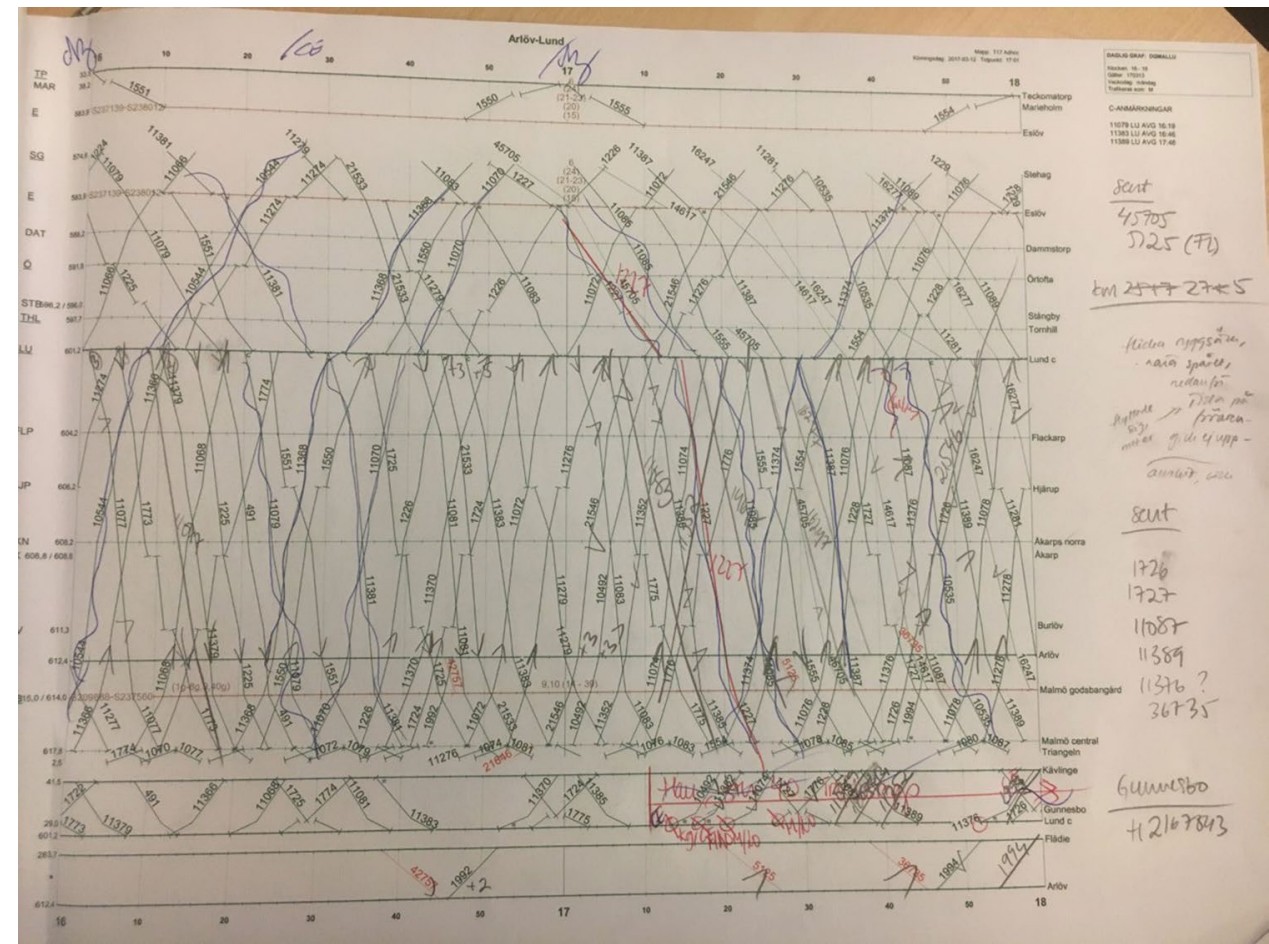

This ongoing discussion that TC4 refers to is usually not noticeable for a novice. However, the tacit knowledge of experienced traffic controllers makes it possible for them to adjust their individual activities to other work activities taking place in the control room without explicit communication regarding this coordination of activities. TC11 explains how a train leaves one control area and becomes the responsibility of another traffic controller: "When a train deviates from the plan, it might be ahead of the timetable or it might be behind it, we make an oral handover. But when everything goes as planned... there should be room for him [the train]". In this way, silence is a type of communication that provides important information, conveying to the colleagues in the control room that everything is under control (cf. Hollan et al. 2000). With the DC perspective, it becomes apparent that information is not only stored in various kinds of cognitive artefacts, but that it continuously flows between people, digital, and analogue representations. The close relation between the representations in the cognitive artefacts and in the traffic controllers in the propagation of the information flow appears to be an issue not given much attention in prior railway research.

The work role of a train driver is to operate the trains, while following points, signals, and the current traffic plan set by the traffic controllers. The drivers should also maintain a safe and comfortable ride for the passengers and make sure to keep the timetable. The work is highly dynamic due to a variety of train types, geographical prerequisites, and weather conditions that affect how to drive in the most considerate way. Controls, properties, and equipment vary between different types of trains, and while heavy freight trains have slow acceleration and low top speed, passenger trains often have several power cars, are lighter and can accelerate and decelerate more quickly. Train drivers also function as "machinists" that should actively monitor the trains and perform check-ups on engines and brakes.

The work activity of a train driver is in many ways individual and it may even be described as isolated due to the driver being alone in the locomotive with limited possibilities to communicate with others, both colleagues and passengers. The telephone, as an external resource, is their only means of communication and it gives them the possibility to talk to the traffic controller as well as the customer service personnel working on-board the train. However, the train drivers rarely meet colleagues in person and communication between them is scarce.

When it comes to driving the train, TD4 describes it as "It is like a sewing machine, you only need to step on the gas"; however, this is only one small part of what the role of a train driver entails and the full picture is more complex. In fact, train drivers adapt their driving behaviour to the current situation and in accordance with Jansson et al. (2006), this study shows that the drivers visually search the surroundings for different types of information based on their current location. For example, when starting their work day, TD1 explains that "I always take a walk along the platform. I like to see the passengers, and many of them have questions. It is also good to get a sense for the atmosphere among 
the passengers". When the train has left the platform, the driver is usually fully focused on what is seen ahead (signs, points, and signals) and changes in speed limit displayed in the ATP as a cognitive artefact. They try to optimise their driving behaviour and merge the situated circumstances with the official traffic plan. TD4 has turned this into a personal challenge and expresses that "It is fun to try to hit the zero", which indicates that he tries to arrive at each train station at the exact same time that is presented in the timetable. This is another instance of the coordination between several internal and external structures in the organisation and propagation of information flow involved in the train driving task, which also unfolds in both time and space.

When approaching a train station, the driver's attention shifts and the centre of attention is instead the closest surroundings, i.e., people on the platform, trains nearby, and potential level crossings. When approaching a station, TD2 tries to estimate the length of the platform and mumbles to himself "I wonder if there is enough room for us here... How long is that one? [he counts the carriages on a train along the opposite platform]. Six carriages and a locomotive. Then let's do it like this... I think this is good" he says and makes a full stop when the locomotive is just in front of the platform. This leaves the locomotive outside the platform area, which apparently was a bit short compared to the full length of the train. He leans out the window to make sure that all carriages are next to the platform so that the passengers safely can enter the platform.

Clearly, there is more to driving a train than to "step on the gas". The drivers are also concerned with how people behave in public and respond to fragmented information based on the behaviour of others in attempts to predict future conduct of passengers and people moving along the platforms. TD2 explains that "You have to check for people that might pose a risk in some way... But usually you will just see this [he points out the window to a man walking beside the train] — he is taking his time, trying to find a carriage with empty seats instead of just getting on the train. We are $30 \mathrm{~s}$ behind the timetable now because of him". While some train drivers express their annoyance for this behaviour, others have developed strategies to try to influence the indecisive passenger. TD4 explains that he usually "ventilates the engines", which makes a humming sound, to signal to people nearby that the train is getting ready to leave the station. The practice of "ventilating the engines" may seem as a trivial activity; however, this activity relies upon experience and a body of actionable knowledge regarding passenger behaviour and how to shape human conduct at train platforms. As previously mentioned, similar behaviours have been observed in the London underground, where train drivers use the sounds of the closing doors to encourage passengers to either get on-board the carriages or to step away from the train (Heath et al. 1999).
These are all examples of how drivers are situated in the moment and uses their experience to interact with the physical and social surroundings and adapt to the conduct of others. Although a lack of formally provided information, the drivers observe and gather the information needed to allow them to anticipate, perceive, and account for situations they might encounter. This means that within the distributed socio-cultural and technical system of operational railway traffic, information is seamlessly flowing and propagated between the entities. The various kinds of representations transform when they shift and intertwine the borders of tacit knowledge and cognitive artefacts, including information provided from the locomotive's engine, spoken language, and telephone.

Traffic controllers and train drivers are located at different places, part of different organisations, have different strategies and processes for doing their work, and different tools to support them. Despite this, both partners possess skills and knowledge the respective other might lack and it should, thus, be emphasised that traffic controllers and train drivers need to cooperate in the execution of railway traffic. One the one hand, the traffic controllers are the ones situated with a multitude of information sources and insights into the overall traffic situation. By having access to the traffic control system, which displays the status of the infrastructure (i.e., which sections of the tracks that are free, occupied by a train, or set for a train to soon enter) the controllers have the "allseeing" perspective. Meanwhile, the train drivers usually lack updated information about the current traffic plan and the overall traffic situation. On the other hand, the drivers should be considered as the partner with rich, situated local information, since they are fully informed about the state of the train they are driving, the status of the tracks, and their prerequisites of reaching the next station in accordance with the timetable. They also have the possibility to monitor the surrounding environment and make use of tactile and aural feedback to get information about the weight of the train's load, influences of weather conditions on the tracks etc. This is "actionable knowledge", i.e., knowledge that can be acted upon and applied to solve real-world problems (Evans et al. 2017) and that is essential for the realisation of the traffic plan. The traffic controllers do not have direct access to this situated information and no way of controlling that their adjustments to the traffic plan are realistic given the current circumstances on the tracks. In fact, and contrary to what their work title might suggest, the controllers to a great extent lack the possibility to control trains other than to define their routes and stops. Accordingly, none of the two partners have the full picture, but both have great influence on the execution of the operational traffic. Hence, they need to share their perspectives with each other to reach the goal of an efficient traffic with minimal delays and disruptions. Although the partners are separated in space, this 
overarching purpose of their work tasks makes them part of the same process of cognitive work. The power of the cognitive system composed by the traffic controllers, train drivers, and the internal and external resources (technologies and cognitive artefacts) they use is not determined by the capacity of either one of the inherent components. Instead, the cognitive activity is bound to the act of coordinating these components in the composition of a cognitive functional system. Examples from this functional system and coordination activities of Swedish operational railway traffic are described below.

\subsubsection{Distributed cognition in cooperative railway traffic}

Although the traffic controllers often describe their work tasks with word such as "a computer game in which we don't see the real world" and "a giant puzzle that you can never finish", they take great pride in their profession and believe that they are doing an important job. They often appreciate the problem-solving aspect of the tasks: "Trying to save a minute here and there, that is the fun part" as TC11 expresses it. His colleague, TC17 adds, "It is incredibly satisfying when everything works... when everyone is in the game."

The traffic controllers' work environment is highly social. They are constantly surrounded by other traffic controllers, which creates an environment in which coordination and synchronisation between the traffic controllers relies much upon overhearing each other. For example, TC2 describes that he is constantly listening for someone to mention "his" train numbers (the ones representing the trains that are located in the control area he is monitoring). In fact, to replan the traffic is often done aloud, as if the traffic controller talks to himself. The utterances are low-key and they rarely bring a verbal response from others in the control room, but the controllers hear each other and adapt their work with respect to the information that is present and flows in the control room. One example of this is when TC4 receives a phone call from a driver about a malfunctioning signal. In an attempt to collect as much information as possible, TC4 asks the driver multiple questions about the signal and in what way it is malfunctioning. Once the conversation with the driver is over and the traffic controller hangs up the phone, one of his colleagues, another traffic controller working in the same control room, turns to him and says "that signal malfunctioned yesterday too...", upon which yet another traffic controller adds "I had problems with that signal on Monday. Did they never fix it?" Suddenly the whole control room is invested in the situation with the malfunctioning signal and, without leaving their own work stations, the controllers provide information to the others in a manner of work practice that Heath and Luff (1992) describe as "talking to the room". This means that the controllers fill in each other's information needs more or less unintentionally by speaking out loud. In this example, the shared information was about the signal and earlier situations involving that particular signal. This activity took place for a few minutes, but quite soon, the room went silent again and the controllers' attention was once again directed towards their own tasks and the traffic situation they were handling. However, approximately $5 \mathrm{~min}$ later, a colleague approaches TC4 and says "the signal will be fixed tomorrow" (TC2). This colleague had, on his own initiative, called the maintenance crew to check the status of the errand and to explain the situation that was revealed in the control room when several of the traffic controllers had experienced difficulties with the malfunctioning signal.

In this episode, it is clear that, when information is represented "out in the open", there is no need for the information to be internally represented. This seamless integration of at first glance individual work activities demonstrates the coordination of work, where the performance of different tasks by several persons leads to a joint result.

Yet another example of team performance among the traffic controllers was observed when the signals leading in to the railway yard malfunctioned. The railway yard is a complex series of tracks used for storing, sorting, loading and unloading railroad carriages and locomotives. These tracks are off the mainline to make sure that they do not hinder the traffic flow. However, when the signals malfunctioned, no train could either enter or leave the railway yard and while the responsible traffic controller called the technicians, trying to find someone that could repair the malfunctioning signals, a queue was building up by trains awaiting to get access to the yard. These trains risked to disrupt the traffic flow on the mainline, and meanwhile, the responsible traffic controller was busy trying to solve the issue with the signals, the other controllers in the control room, started to make phone calls to the surrounding traffic control centres asking them to hold back trains from entering the control area in which they were confronted with this complicated situation. They were also contacting some of the train drivers, informing them about the situation and, if possible, re-planned their routes. The traffic controller who was responsible for the railway yard never asked for this type of assistance, but just as in the previous episode, they overheard him talk to technicians and their actionable knowledge made them understand what needed to be done and how to act to solve the situation. A short moment arose when this coordination was acted out and then the silence spread once again in the control room.

These examples show that although the controllers are engaged in individual tasks, they still remain sensitive to the conduct of colleagues. Phone calls and brief utterances function as coordination mechanisms for the traffic controllers' via ongoing sense-making practices for keeping an updated situated understanding of the overall traffic situation. The 
individual actors actively working in the control room minimises their workloads by allowing information to be available and flow in the environment. When information is available primarily via social interactions, the structure of the cognitive work becomes an unplanned side effect of the interactional structure as such. This is clearly shown in the two episodes above, in which malfunctioning signals were handled in an unforeseen manner by the interactional structure of the control room. The cognitive processes are distributed across time, space and the members of the group during the coordination of their individual, but collaborative, work activities. To achieve this joint result, several coordination mechanisms that have the capacity to handle the propagation of representational states through the system are needed. This way of acting displays that the coordination of different representations (external and internal) is an emergent property of the system as a whole and cannot be reduced to a property of a certain entity (human or cognitive artefact). This holistic and emergent view is the very foundation of the DCog approach; the total sum is more than the sum of the individual parts due to emergent properties of the socio-cultural and technical system.

When it comes to the train drivers, they are not part of a socially shared situated work environment and they do not have access to the information that is transformed and propagated in the interactional structure taking place in the control room in the conduct of "talking to the room". Similarly, they cannot overhear their train driving colleagues. They do, however, listen for other types of information, for example, the sounds coming from the train, sounds made of the friction of the train moving against the track, etc. and in a way, this physical environment is the interactional structure that the train driver is an active part of. In the same way as the controllers, the drivers are actively listening for subtle information that can be used in their sense-making efforts of determining how to drive in the most considerate way. The skilled embodied practice of being able to hear and recognise anomalous sounds that reveal relevant information has previously been introduced as professional hearing (Andreasson et al. 2017a).

As a complement to this situated information, the drivers often talk about how they wish to be able to overhear what the traffic controllers are conveying to their fellow train driving colleagues. The drivers are especially wishing for a broadcast to all drivers in a geographical area when the traffic controller have access to general information, for example, if there has been an accident that will delay several trains. In cases like this, the drivers would like to know about what has happened and "how they have planned to solve the issue. If they would broadcast to all of us, we [the train drivers] would not have to call, and sometimes even wait in a telephone queue, just to get the same basic information" (TD3). Clearly, this wish stems from a need for a type of information that is general and related to the overall traffic situation. TD7 describes that "there are situations when my train is not directly affected, but it would still be good to know if something big has happened and how the situation is being handled".

Interestingly, both parties address their need for more information, and while a broadcast would fulfil the drivers' wish, it is likely to simultaneously decrease the amount of information provided to the traffic controllers by train drivers calling and reporting things they have seen along their route. The traffic controllers are centralised, working from a distance; however, the train drivers are just as distanced from other trains except their own. Despite this similarity in conditions, the two work roles have different reach in time and space: the train drivers may be affected by happenings outside of their physical reach (their location) or things that happened some time ago and have little control on how to handle it, while the traffic controllers have a broader grasp of the general traffic situation and the possibility to affect the situation independent on the location or the timely aspects. In fact, the traffic controllers remote work process includes two different time frames and two different ways of working: one requires to act directly on feedback from train drivers or from the traffic control system and the other involves to plan ahead and prepare point and signals. This is usually done well before the train is getting in the vicinity of the signal/point in question. TC10 describes that "I finish as much as possible. Then, I monitor how it works". The carefully done preparations enable the traffic controllers to foresee phone calls from train drivers. One example of this is when TC1 points to the screen, where a new train number just had appeared and says: "He will probably call soon. He wants to go to... [he uses the time-distance graph to see where the train is going and points out the location on the screen] ... he wants to change direction of his train". The traffic controller is now prepared, and when the train driver calls a few second later, the train's identification number is displayed on the telephone, the traffic controller locates the train number on the computer screens and answers the phone; meanwhile, he is making the requested changes in the traffic control system. Due to his preparation before the phone call, the traffic controller is certain that he knows what the request will be about. The conversation between the two is less than $1 \mathrm{~min}$ long, much due to the preparations made beforehand by the traffic controller. This is an example of transformations of representations: from external representations in the cognitive artefacts to internal knowledge concerning the reason for why the driver is calling. The process of planning ahead and preparing for future tasks (and future trains entering the control area) enables the traffic controllers to spread out the workload over time. By doing things ahead of time, the task gets easier and the nature of the task performance is transformed and distributed through time in a way that makes the 
products of earlier events transform the nature of later events (cf. Hollan et al. 2000). The representations of trains that are shown in the time-distance graph helps the controllers to foresee what tasks that needs to be done. This supports them in their extended reach through time and space and enables them to plan for future events taking place in locations far from their own.

Although much of the overall, general information about the traffic flow is unavailable to the drivers, they still manage to play an important part in the distributed socio-cultural and technical system and the organisation of activities within this system and its separate members. There is a multitude of possibilities for how to combine the distribution of human effort across the components of a cognitive work task, which allows for a structure that spreads the workload across the members of the team, thereby avoiding to overload any individual. The distribution and synchronisation of cognitive effort among the traffic controllers, and between them and the train drivers, is an essential part of the organisation of behaviour that enables the system to successfully run the railway traffic. This distribution makes it possible for the workers to avoid discoordinations in the socio-technical system in which someone undo someone else's work, collisions in work tasks, and conflicts between actors working at cross-purposes. It also enables a temporally parallel activity divided between the workers and makes it possible to avoid bottlenecks in the work process. Without an efficient coordination between traffic controllers and train drivers, both conflicts and bottlenecks may arise without communication between the roles. In this coordination of activities between persons and devices, much of the organisation of behaviour is removed from the individual worker and is instead given to the structure of the system with which the workers are coordinating. In fact, this is what Hutchins (1995a, p. 200) describes as the meaning of coordinating: "to set oneself up in such a way that constraints on one's behaviour are given by some other system".

\subsubsection{Situated knowledge}

In the control room, each workstation is equipped with 8-12 computer screens that display the traffic control system and allows the traffic controllers to manipulate the traffic. Both the traffic control system and the time-distance graph are different kinds of representations of the actual railway traffic. In fact, these representations are the closest to the real world as the traffic controllers can get. By monitoring the traffic control system, and to have the graph as a key to how the traffic should run, the traffic controllers collect the information needed to act upon and to understand the current traffic situation so that they can identify potential conflicts or future traffic problems. This is challenged by the fact that less trafficked parts of the tracks (often leading to factories or railway yards) are not displayed in the traffic control system. However, the controller still needs to be aware of the trains in these areas and provide them with the proper signals for entering or leaving these "hidden" parts of the tracks. This requires a tightly coupled coordination of internal and external mechanisms, where internal structures are projected onto external structures to create a greater meaning to the features observed in the computer system and in the time-distance graph. In fact, when the traffic controllers monitor the track diagram that is shown in the traffic control system (see Fig. 5), they do not see lines of varying thickness as a novice would, but railway tracks, stations, platforms, and trains. Although the traffic control system represents the actual railway traffic, the representation does not map well to the real world. For example, almost all features such as railway tracks, platforms, and trains are displayed as lines without a clear distinction and the geographical references to stations and towns that are made in the interface does not correspond to their actual geographical positions. The shape of Sweden is elongated and the main parts of the railway tracks run from north to south. Still, the traffic control system should be read horizontally which creates a mismatch between the true geographical position of a certain location and its represented position displayed in the graphical user interface. Irrespective of this mismatch, the traffic controllers manage to "see" the entities of what is displayed in the system as well as their inward relations. Clearly, experienced railway traffic workers have acquired considerable knowledge on how to best fulfil their tasks and have developed so-called intuitive, situated knowledge (Clancey 1997) as a product of the activity, context and culture in which the knowledge is developed and used (Brown and Collins 1989). Their situated knowledge enables the traffic controller to see the situation based on the available information and transform it to actionable knowledge using "intuition" and extensive experience.

Due to the traffic control system being the main cognitive artefact for the traffic controllers, the accuracy of the available information is of high importance. However, the railway tracks are divided into segments and the information shown in the traffic control system is limited to which of these segments that are occupied by a train. The segments can be several kilometres long, and the length that is displayed in the computerised system do not correspond to the length of the actual segment. Consequently, it is difficult to determine the exact position of a particular train within each segment and the only time the traffic controller gets real-time information about the position of the train is when it moves between two segments. This does not, however, seem to bother the traffic controllers. TC2 explains that "I see the trains, I know exactly where they are, they are there [he points to the red lines presented in the user interface]". This is one example of what Goodwin and Goodwin (1996) 


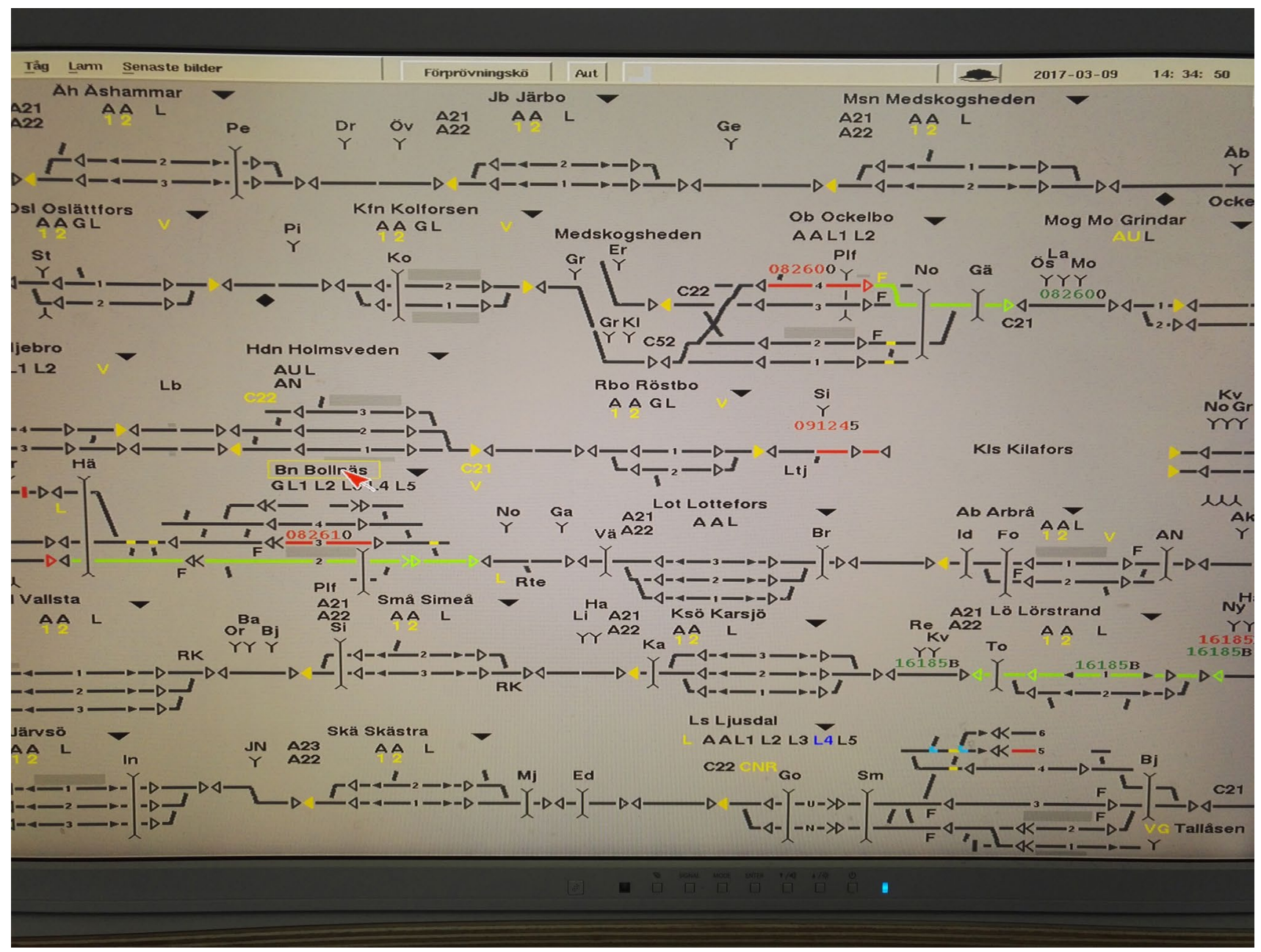

Fig. 5 Screenshot of the traffic control system. The black lines represent the railway track, red lines represent a segment of the tracks that currently is occupied by a train, and green lines indicate that a train

describes as tool-mediated seeing. This is characterised by the action of seeing aspects that are relevant for a certain task only through the use of tools and artefacts (e.g. when a submarine operator uses the periscope to see above the surface). The traffic controller knows, where the trains are without actually having access to the information. However, based on the previous transitions they have seen when a train passes from one segment of railway to another, they can make assumptions that allow them to derive a train's current position and speed.

The traffic controllers are skilful when it comes to successfully use and interpret the information presented via the traffic control system, but they still need to actively seek complementary information to gain actionable knowledge. This is especially done in interaction with the train drivers that can provide context to what is shown to the traffic controller in the graphical user interface of the traffic control system. One frequently occurring example of this is when has signals that show clear through the points. The numbers above the lines indicate things such as the identification number of each train and numbers for each point and signal

a traffic controller notices that a train is standing still for a long time at a platform. In these situations, the controller knows that the train is standing still although the timetable says that it should be on its way, but he or she has no information about why. For this reason, the traffic controllers are highly dependent on the coordination with the train drivers and the information they can provide. Since the train driver are outside of the control room and part of the traffic situation, they do not have to rely on a representation of the real world but can instead experience it first-hand. TC15 explains that "since we cannot see what is happening in reality, that information [that the drivers contribute with] is worth gold. It is essential for our job that we get that information". One issue with this way of seeking information is that the traffic controllers phone call sometimes can disturb the train drivers. For example, in the case of the train standing still by the platform, the traffic controller wants to know what has happened and what the prognosis is. He/she needs to know if 
the train will be standing still for a longer period of time and, hence, if it is needed to change the traffic plan concerning other trains entering the station. The train driver on the other hand might be busy with troubleshooting the train, trying to solve the problem and, therefore, do not prioritise a conversation with the controllers to inform them of the situation.

Hollan et al. (2000) argued that representations do not only refer to something other than themselves, but that they also are manipulated by humans as physical properties. Hence, humans frequently shift their attention from the representations to attending to the thing being represented. In railway traffic, the drivers have access to the thing being represented (the train, the railroad tracks, signals, etc.), while the traffic controller is restricted to the representations provided by the traffic control system. For the sociotechnical system to shift from attending the representations to attending to the thing being represented, the traffic controller and train driver needs to cooperate and coordinate their activities.

The coordination between different types of internal and external structures are central to the unit of analysis in DCog and in the described coordination we can see how the structure of the artefacts, together with internal structures (strategies for seeing) enables the traffic controllers to operate the control system. Consequently, the combination of the cognitive artefact, i.e., the traffic control system and the graph, information from the drivers concerning available landmarks in their surroundings, and the cognitive strategies for seeing that the controllers have developed becomes the structured representational medium of a functional cognitive system for train traffic control. To know when to seek further information and how to interpret the information about landmarks that the controllers have not themselves seen emphasises the power of this sort of knowledge.

\subsubsection{Organisation of team performance}

Traffic controllers and train drivers have access to fundamentally different information and both roles have information that is of value for the other. Currently, there is no seamless propagation of information flow between them. However, the detailed information about the overall traffic situation that the traffic control system provides the controllers with has often been highlighted as the most important, functioning as a key coordination mechanism, and as a source of information that everyone involved in operational railway traffic need access to. This has resulted in the development of different types of Driver Advisory Systems (DAS) that are portable for the train drivers to bring with them while driving the trains. These systems provide the drivers with more information than what was earlier accessible to them; however, the type and volume of information are still not

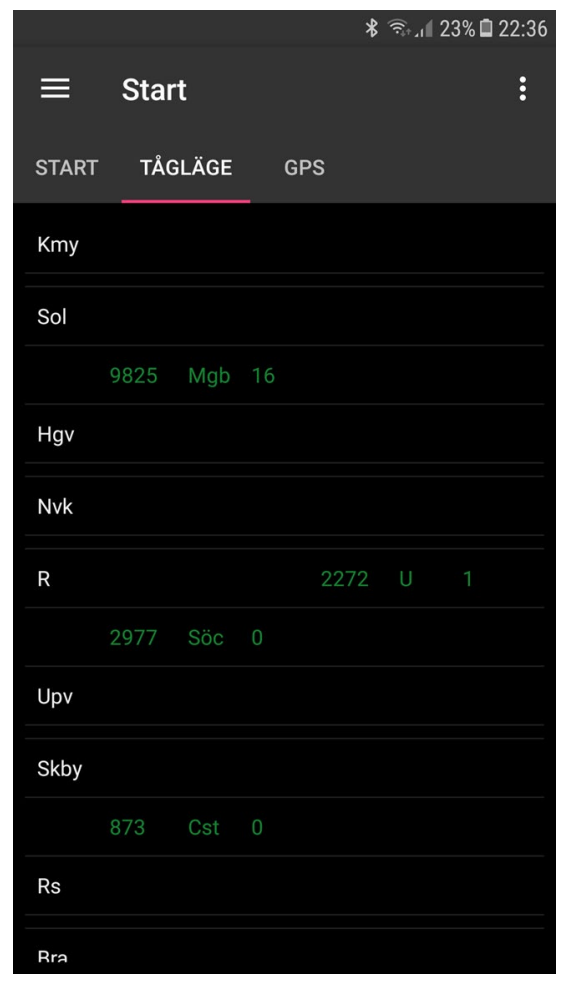

Fig. 6 Screenshot of the DAS in which the driver gets information about other trains located in his near surroundings. This image tells us, for example, that train number 2977 is approaching the train station Rotebro (abbreviated to an $\mathrm{R}$ in the image), the same location where train 2272 currently is positioned. In this image, all trains are following the timetable (and, therefore, displayed in a green colour instead of red, which would indicate that a train is delayed)

comparable to the information presented to the controllers in their cognitive artefacts.

The train drivers participating in this study all work at Sweden's largest railway undertakings and the company has developed a DAS for their drivers to use. The technical solution is a mobile application that runs on a tablet or smartphone. Besides providing the drivers with real-time information about the train's position and advice regarding speed and how to drive in an energy efficient manner, this DAS also displays the position of a limited number of trains in the nearby surroundings and applies a colour code to display how well those trains are following the timetable (see Fig. 6).

During the study, it was observed that the train drivers were paying much attention to the information presented digitally in the DAS as a cognitive artefact. One example of this is when the train driver encounters an unexpected stop signal. As soon as he notices the signal, he takes a quick peak in the DAS to find an explanation. When this does not help, the DAS did not present any clarifying information to the stop signal, the driver calls out to the passengers to let them know them that he is approaching a signal that 
requires him to do a full stop. Once this is done, he calls the control room and is automatically directed to the traffic controller in charge. He presents himself with his name and the train's identification number and asks about the reason for encountering a stop signal. After a short conversation, he finishes the phone call and turns to the researcher to explain that a malfunctioning point had forced the traffic controller to temporarily lower the speed limit. Due to the temporary nature of the issue, the speed limitation shown in the ATP would not be updated but would instead show the original speed recommendation, which was why the traffic controller had decided to stop the train and make oral contact with the driver. Once the driver was informed about the issue, the traffic controller changed the stop signal and we could pass through the point at a significantly lowered speed.

A few hours later, when going back the same way as earlier, the train driver is aware of the malfunctioning point and describes that he would like to call the traffic controller and ask for a status update. Suddenly he receives a phone call from a traffic controller who describes the same problem that we encountered earlier. Together the traffic controller and the train driver decide that the driver should exceed the speed limit (but still within safety regulations) to get a head start and arrive at the malfunctioning point ahead of the timetable. Once the conversation is over, the train driver turns to the first author and says happily "Yes! That is how it is supposed to be done. If I have the information I can be adaptable, but if I am unaware of the problem we will be delayed. It is as easy as that". In this example, the driver and the controller used actionable knowledge when they made a piece of information actionable in a way that created value, i.e., they used the information about the malfunctioning point to adjust the speed. This enabled us to arrive at the end destination in time, not affected by the lowered speed limit that otherwise could have resulted in a delay.

In the episode above, the traffic controller and the train driver managed to create a coordination between the cognitive artefacts they use (mainly the DAS and the traffic control system) as well as a coordination of those activities with the activity of coordinating with each other. This is what Hutchins (1995a) refers to as a high-level coordination, which lessens the cognitive load by distributing it to the social coordination of the situation. In railway traffic, this happens all the time. In the example above, several activities took place more or less at the same time: the traffic controller interacted with the traffic control system, the train driver interacted with the DAS, and they coordinated these separate activities with the communication and coordination between themselves. In this distributed coordination, both workers independently collected needed information about how to best handle the malfunctioning point from the different representational formats available. This required a tightly coupled coordination of external and internal mechanisms, where internal structures were projected onto external structures to create a greater meaning to the features observed in the DAS and the traffic control system.

Much of the coordination observed does not require oral communication between the workers. Instead, a range of artefacts of the socio-cultural and technical system is used to enable coordination between the distributed parts of the system. Examples of these artefacts include the signalling system along the tracks and the information regarding speed limitations provided by the ATP equipment in the locomotive. Both these are examples of cognitive artefacts that carry information from the traffic controllers to the drivers. During one of the observation sessions in the locomotive, TD4 notices that the signalling system is guiding him to another platform than the one he was expecting. He explains what he thinks is the reason for this sudden change: "he [referring to the traffic controller] changed us from platform 1 to platform 2 , since the meeting with the other train was cancelled and platform 2 does not have level crossings. This allows us to drive a bit faster and saves us some time".

In this example, the traffic controller was responsible for changing the plan, he mediated the communication to the train driver via the signalling system, whereupon the driver understood what has happened and executed the new and improved plan. In this mediated coordination of activities, the workers' cognitive load was distributed between them and thereby lessened. Clearly, the cognitive workload conducted by the socio-technical system of railway traffic is not equivalent to the cognitive workload that the individual worker is facing.

One might think that the more the drivers use the DAS, the less oral communication is needed between the drivers and the traffic controllers. However, it should be noted that the DAS does not bring the drivers all available, or all relevant, information. It should also be noted that the DAS enables the drivers and give them an increased opportunity to a proactive driving style; however, the traffic controllers know little about what is displayed in the DAS and have mixed feelings towards the technical advancements and the new information structure it brings. When asked about the increased use of DAS and if it has brought any noticeable effects to the traffic controllers' work situation, some changes to the work process is mentioned. For example, TC15 says:

"What we [the traffic controllers] have started to notice now, with the tablet [referring to the DAS], is that the drivers have started to take their own initiatives... You may think: 'I can see that a train is running late but since we are supposed to meet soon, I will start to slow down now so that I am better off for that meeting point.' But meanwhile you are doing that, I [as a traffic controller] have already changed the location for the 
meeting, but you don't know that. And then it will be a big mess...".

What TC15 is referring to is the conflicts that might arise when the train drivers make decisions on how to handle traffic conflicts without communicating this potential solution with the controllers. In the example TC15 describes, the traffic controller has re-planned when and where the two trains will meet with respect to the train that is delayed. This plan will only work if both of the train drivers are maintaining their normal speed and follows the signalling system as a coordination mechanism that will guide them to the new meeting location. This is an example in which the work structure in the socio-technical system spreads the cognitive workload across the workers but do not successfully avoid overloading any of the individuals due to a discoordination which results in conflicts and work being cross-purposed. Although the DAS makes the drivers informed enough to make decisions and find solutions to local traffic conflicts, it is a fact that the traffic controllers are the ones situated with the main sources of information, having the overall picture, and they are still the ones responsible for re-planning the traffic when necessary. TC14 expresses "they [the train drivers] do not have access to the time-distance graph. They do not see the whole picture. They do not see the problems that I see". A similar line of thought is expressed by TC17 during the pairwise interviews:

"the problem is that I am responsible for all the trains in the control area and the driver's task is limited to his own train. This creates... not a conflict but... different perspectives". TD1 agrees and explains that: "Yes, I can never be responsible for more than my own train. I can see some information about meetings and the trains that are in front and the ones that are behind me. But in the limited information that I have, I cannot make the assessments as you do [he points to the traffic controller]. I still only see my little world".

This type of comments, indicating a certain degree of discontent are common among the traffic controllers when talking about the DAS and they all agree that its increased use has fundamentally changed their current work practice. However, also positive aspects are mentioned. For example, TC12 describes that "Sometimes they [the drivers] call for things such as: 'I see that I'm planned for entering platform $\mathrm{X}$, but that is potentially not a good idea since I'm long today [referring to the length of the train]'. Those calls are great, because the train's length is not displayed here [she points to the traffic control system]". Naturally, the traffic controller can gain access to information about the length of the train but this piece of information is not properly displayed in the traffic control system, thus, requiring the traffic controller to login to another system in active pursuit of that particular piece of information. This is normally not an activity that the traffic controllers do regularly. This is a good example in which the information available to either one of the two roles is not enough to successfully plan and execute the railway traffic. Instead, it is when the traffic controller and the driver share their information with each other that they can find the best solution. Although this study did not specifically focus on usability issues of the various digital cognitive artefacts used in operational railway traffic, the above example clearly indicates that lack in usability may result in problems with synchronisation of information and can thus bring severe consequences to the outcome of the work being done. The coordination between computer-supported work tasks and other analogue works tasks often requires a higher cognitive workload in the users (in this case: train drivers and traffic controllers), and lack of usability may give rise to unnecessary cognitive workload.

The inclusion of DAS as regular equipment for the drivers has brought changes in the information structure, which in turn has changed the work roles and the strategies and work practices applied. Clearly, technology affects the behaviour of people, and the behaviour of people affects the working of the technology, thus making technology and the people in a work system interdependent and inseparable. Accordingly, the technology used transforms the nature of the work tasks and changes the cognitive requirements of doing those work tasks. The usage of DAS creates an interesting meeting between the controllers and the drivers, challenges the old work structures and adds new conditions for a proper coordination of work activities. Naturally, changes like these tend to raise separate opinions and emotions and in this case, when the traffic controllers are used to being the sole owner of information regarding the overall traffic situation, they may feel replaced or questioned in their official role as decision makers and problems solvers of traffic conflicts. It is also noticeable that the two work roles have somewhat different prioritisations. A striking detail is the drivers' tendency to talk about the passengers and their feelings of responsibility towards them. TD4 describes a strategy he uses to keep the passengers content when they are approaching a stop signal. He explains: "I slow down well in time before the stop signal and drive very, very slowly until I arrive at the signal. It is better to do it like that than to drive to the stop signal and be standing still there. In this way, the passengers might not even notice that we have stopped". This stands in stark contrast to the traffic controllers that express how they try to ignore the fact that some trains have passengers on-board and other have not: "That should not affect us. All trains should be handled the same" (TC8). One traffic controller even describes a situation, where she leaves work to meet her daughter at the train station: "I was standing on the platform, the train arrives and hundreds of people poured out. It was so surreal that I had been looking at these train all 
day [via the traffic control system], seeing them as these red lines and without reflecting on the fact that all these people are part of it" (TC16). It is clear from examples like these that the traffic controllers prioritise the overall traffic (the traffic flow), while the train drivers prioritise their own train and the passengers on-board. Differences like these challenge the coordination, synchronisation, and organisation of behaviour within the socio-technical system, addressing the need to consider how the design and development of various tools and cognitive artefacts mutually affect and transforms the work practices within the distributed railway system.

\subsection{Reflections on findings}

In this study, we have seen how a successful operational railway traffic is dependent on organising principles of the coordination between the traffic controllers and train drivers and the social, cultural and material resources they use in their everyday work. The work practices described are rarely based on formal work instructions but should instead be described as a result of the workers' acquired situated knowledge. This knowledge is instead based on the workers' experience and a product of the activity, context, and culture in which this knowledge has been developed. Brown and Collins (1989) describe this as situated knowledge. In the episodes presented above, it has been shown how the workers apply current and emerging work strategies for generating relevant knowledge from small pieces of information presented, for example, in the traffic control system. This action is a result of the workers situated knowledge, which according to Dreyfus (1992) requires a contextualised type of "common sense" that the human being is equipped to develop by being embodied and situated in a physical, social and cultural world. As such, the situated knowledge is difficult to make explicit. Instead, the knowledge is bound to its context of use and often results in the development of actionable knowledge, i.e., knowledge that can be acted upon to solve real-world problems.

In this study, we have seen how controllers and drivers bring different types of situated and actionable knowledge to the joint task of executing the railway traffic. Taken together, this adds another dimension to the knowledge required of the workers, which we denote as enacted actionable practices. This concept incorporates both the above terms, since the knowledge needed by the traffic controllers and train drivers has to be both situated in the physical, social and cultural world of operational railway traffic, and actionable for the workers to be able to act on their knowledge and develop best practices that are properly adapted to the challenges presented by the real-world problems occurring in railway traffic. The combination of the workers' situatedness and their actionable knowledge on how to best handle the situations that occur enables them to develop practices that ground their cognitive work to the world, i.e., the practices are enacted to the world in which they are being manifested.

\section{Conclusions and discussion}

In this paper, we have reported on a study of the ways in which traffic controllers and train drivers coordinate their actions to successfully execute the railway traffic. On an overall level the DCog perspective brought forth the close interrelatedness of various kinds of computerised technology, additional cognitive artefacts, and people, in the functional system.

The results provide a description of the complexity of collaborative work, and display how individual tasks are systematically coordinated with the actions of others. Each individual involved in the operational railway traffic generates information needed by the others. In an environment like this, collaboration, synchronisation, and the coordination of activities, as well as the ability to share information in a uniform and transparent way, anywhere and anytime, are essential components in providing a safe and efficient railway traffic. The episodes depicted above describe a particular kind of social organisation and one that permits the individual workers to combine their efforts in ways that produce results that could not be produced by any individual working alone. This effect of social organisation is to a large degree invisible, but often ubiquitous in modern workplaces. With the application of DCog, we can step inside the socially distributed system, and although processes inside people's heads still remain hidden, a great deal of the organisation and operation of the socio-cultural and technical system is made directly observable (Hutchins 1995a). By this, we can begin to answer questions such as: What are cognitive abilities used for? What type of tasks are encountered in the everyday world? Where shall we look to understand and explain human cognitive accomplishment? (Hutchins 1995a, p. xiv).

Little of what has been seen in this study when it comes to the coordination of activities in the complex net of tasks active in operational railway traffic is stated in formal descriptions of work. Instead, the work environment for the traffic controllers and the train drivers is cultural and created by the human to organise cognitive activity and support the construct of thought. Hutchins (1995a) describes how "Humans create their own cognitive powers by creating the environments in which they exercise those powers". What has been seen in this study is how these environments create a culture in which partial solutions to frequently encountered problems is gathered over time and become intertwined. Hutchins (1995a) uses Simons (1981) famous example of how the movements of an ant on a beach tells us more about the beach than the ant itself and describes how the beach is 
likely to form paths to food sources visited by the ants over and over again. He concludes the examples by stating:

“... a dumb ant has been made to appear smart through its simple interactions with the residue of the history of its ancestor's actions. ... in watching the ant, we learn more about the beach than about what is inside the ant. And in watching people thinking in the wild, we may be learning more about their environment for thinking than about what is inside them" (Hutchins 1995a, p. 169 , emphasis added by the authors).

As identified in this study, the traffic control system used by the traffic controllers does not provide information concerning the exact position of a train, or if a train is having difficulties of some kind. Neither does it display platforms that are closed or reveal information about ongoing maintenance work on the tracks. Technology is usually implemented with the intention to provide the users with help and support in complex situations; however, the lack of relevant and all-inclusive information in the traffic control system makes the technology to a large degree redundant. The same goes for the technical cognitive artefacts available for the drivers. Instead, it is the socio-cultural organisation of individuals tasks and activities performed by the traffic controllers and drivers, and the ways in which information is continually distributed between them, that provides them with the possibility of using the tools and technologies at hand and that enables the successful execution of railway traffic. The usefulness of the traffic control system, the DAS, and the accompanying cognitive artefacts, relies upon a collection of tacit practices and procedures (actionable knowledge) through which controllers and train drivers coordinate the information flow, monitor, and complement each other's conduct. The possibility of coordinating tasks and activities within the distributed functional system, rests upon these practices, which are socially organised, largely communicative, and grounded in the workers' situated knowledge.

As traffic control becomes increasingly centralised, the distance between the traffic controllers and the train drivers grows and instead of physically meeting each other at the train stations, their only means of contact is now the telephone. This organisational change put demands on both controllers and drivers to have greater knowledge of the requirements and constraints of their collaborators work, including both humans and technology. This is not an easy task and it gets even more cumbersome considering the increased levels of automation and the fact that autonomous systems are wrapped by human control, affected by assumptions, plans, and intentions made by the human designer (Mindell 2015). Mindell (2015, p. 10) phrases it: "How a system is designed, by whom, and for what purpose shapes its abilities and its relationships with the people who use it". Given the essential role of tacit practices, coordination activities, and situated knowledge for the successful execution of railway traffic, it is highly important to understand these underlying organisational structures to develop automation that fully supports the actual work in the socio-technical system. The popularity of developing advisory systems for the drivers (DAS) has put forward a situation, where this new technology not only provides the drivers with more information, but also affects the whole socio-technical system, changes the relationship between controllers and drivers and, in fact, challenges the coordination mechanisms that lies at the core of operational railway traffic. We find this to be a good example of why a systems perspective is needed in complex domains such as railway and a demonstration of what type of insights a DCog analysis can bring.

A large part of the power and usefulness of DCog is its foundation of being "in the wild" and its commitment to ethnographically collected data. To go where the action is, observe and evaluate how work is done in a naturalistic setting does not only provide high ecological validity but also enables researchers to explore how things really work in these complex contexts, where multiple demands and factors may be at play. This is a cornerstone in research-in-thewild (RITW) approaches such as DCog with the purpose to uncover the unexpected rather than confirming hypotheses or aspects already known (Rogers and Marshall 2017). The cognitive ethnographic practice together with DCog's theoretical traditions bring great power to the framework (Halverson 2002); however, DCog has been criticised for providing few theoretical constructs, except at the basic level of representational states (Halverson 2002; Rogers 2012). This both challenges the researcher' analytical ability as well as provides the opportunity to contextualise the DCog framework in accordance with the context of study. The lack of theoretical constructs also opens up for the inclusion of additional concepts such as, for example, tool-mediated seeing, actionable knowledge, and the development of the new concept that we denote enacted actionable practices. We also found that the importance of time, and the different time frames the controllers and drivers are acting within, made Hutchins (1995a) general concept of coordinating activities insufficient for describing all of the coordination taking place in operational railway traffic. The timely aspects add another dimension to the coordination and we have, therefore, seen the need to add the term "synchronisation" to emphasise that the railway traffic is dependent on synchronised coordination, i.e., actions that are coordinated in a timely manner. Interestingly, the distribution and propagation through time and space challenged the data collection but did not disrupt or restrict that the cognition is being distributed within the socio-technical system.

This study was limited to the organisational settings of Swedish railway. Due to the noisy environment in the locomotive and the distributed work being done in the often very 
large control rooms, it was not possible to collect audio or video data. The main sources of collected data were, therefore, from photographs, informal conversational interviews, and field notes from the observations. We are fully aware of the limitations in the data collection and we do not wish to generalise from this sample to the population of train drivers and traffic controllers. However, it is relevant to acknowledge that the DCog perspective, with the unit of analysis being the whole socio-technical system, brings a valuable approach to naturalistic inquiries. Rogers and Marshall (2017), among others, mentioned that research in situ often need this pragmatic approach to the collection and analysis of data. This way of working enables the researchers to explore and document unanticipated phenomena that can only be revealed through the RITW approach (Rogers and Marshall 2017). In this study, a first step was made in investigating and analysing railway traffic from a systemic perspective. This provides some initial insights on the collaboration and coordination processes involved in the operational railway traffic as these are conducted in the wild.

To sum up, the episodes shown in this paper aim to display the coordination activities in play in operational railway traffic from a DCog perspective. The paper also sets out to illustrate and argue for the inclusion of a systems perspective, and especially the DCog framework, into rail human factors research. The complexity of operational railway traffic requires a vast amount of activities accomplished by traffic controllers and train drivers with their skilful use of tools and cognitive artefacts. The activities taking place within the socio-technical system of railway serves as descriptive examples of the distributed nature of cognition and how emergent cognitive properties arise from coordination and collaboration as the workers "...not just act on the world, but act with the world" (Dix 2002, p. 2). Based on the obtained results, the following implications are important to consider for future railway research:

- To understand what knowledge is required to perform complex tasks, we need a unit of analysis that is not based merely on the individual worker. Otherwise we might be missing coordinating and synchronising interactions and cognitive behaviours relevant for understanding the actual work practices.

- Traffic controllers and train drivers are interdependent and their individual work activities affect each other. This means that in the process of cooperatively executing the railway traffic, the workers accomplish more together than what both could have achieved separately. Thus, operational railway traffic is characterised as the whole being greater than the sum of individual efforts.

- Cooperative work entails a coexistence of the workers while still maintaining independence in their individual tasks. A lack of understanding for the actual work prac- tices and the coordinating activities they entail can result in the development of work instructions and cognitive artefacts that at the most can provide limited support for the work carried out within the socio-technical system.

- The collaborative nature of operational railway work highlights that the development of tools and cognitive artefacts affects and potentially transforms work practices throughout the whole distributed socio-technical system of railway. It is, therefore, essential to design for the whole socio-technical system rather than for one specific part of it.

Our understanding of cognitive work is inadequate if we fail to consider the human as part of a larger system. Most organisations possess knowledge not known to them. Identifying best practices, efficient workarounds, and how work is done in the wild can bring great value and be beneficial, for example, in training of new employees. All that is needed is a systems perspective that makes work visible, and for this purpose, we argue that the framework of DCog is a prominent approach.

\section{Future work}

In our detailed analysis of work and situated practices in operational railway traffic, the collaborative nature of what may seem as individual tasks has been emphasised. The strong interrelation between work roles-individuals conducting individual tasks but connected to each other via a joint information flow-highlights how changes within one part of the socio-technical system is bound to affect also other parts. This points to a number of interesting research opportunities. For example, the emphasis in this study on two of the main actors, i.e., traffic controllers and train drivers, implies that it would be valuable to broaden the unit of analysis even more and include also other work roles in an attempt to increase the understanding of how work is done within this complex socio-technical system even further. The increasing traffic demands, and a higher number of transportations within the same envelope of time, has resulted in frequently changed and updated technical artefacts (including increased automation). For these artefacts to succeed in supporting the workers in their tasks, the current work practices, the workarounds and best practices developed as a result of the workers' experience on how to best conduct a safe and efficient train traffic, needs to be mapped out and taken into account. This research is an initial step towards this goal. For example, the way the traffic controllers "talks to the room" is a key collaboration mechanism for how they create and maintain an up-to-date understanding on the current traffic situation. At the same time, this could be seen as "disturbances" in the control room, but efforts to minimise 
this type of activity could disrupt the whole socio-technical system and create problems that are difficult to foresee. To understand how successful work is done and how to support the workers when it is needed, it is essential to conduct more RITW research with a systems perspective. It should also be mentioned that the findings reported here could have implications for similar socio-technical systems that are still in their early stages of development. For example, motorways with vehicle-to-vehicle and vehicle-to-infrastructure communication, as well as for human operators that monitor this communication with sensor-based surveillance systems, will need to develop coordination mechanisms between drivers and the traffic control centres to enable a successful operation. In a similar vein, future harbour navigational systems in areas with dense traffic are dependent on coordination between both captains and helmsmen, as well as between harbour pilots. When such functional systems continue to develop and turn into more integrated structures-similar in their complexity to the socio-technical system of railway traffic-the framework reported here provides an important contribution to human factors research and opens up for a new and increased venue of future research beyond the often referenced air traffic control systems in aviation.

Another aspect that was revealed to play an important role in the operational railway traffic is the differences concerning time and space. These differences are much due to the traffic controllers being centralised in high-technological control rooms, planning and manipulating the prerequisites for future traffic, while the drivers and their trains are mobile, acting in the current situation, and the drivers often find it difficult to plan ahead. These are fundamental differences built in in the structural organisation for each of the two work roles and these differences, together with the fact that drivers and controllers in Swedish railway are employed by different companies, can easily create a faulty understanding of these two roles as separate and detached from each others' conduct of work. Considering the frequent coordination activities that have been displayed in this study and the essential role they play for a successfully executed railway traffic, this view is nothing but a misconception and it is clear that the work done in one part of the socio-technical system affects all other parts. Nevertheless, the variation when it comes to time and space for the traffic controllers and train driver creates challenges both for research in the railway domain as well as for the workers themselves and their possibilities to create efficient coordination mechanisms. In the purpose of not reinventing the wheel, we suggest to look for theoretical and methodological inspiration in the research community of Computer-Supported Cooperative Work (CSCW), which is concerned with research and systems development at the intersection of collaborative behaviours, social organisation of work, and technology (Kraut 2003). Collaboration between users separate in time and space creates challenges for how to provide sufficient technological support to match the social and behavioural activities. Considering the frequent inclusion of new technology in the railway domain, it is our belief that insights from the CSCW community could shed some light on how to bridge the differences in time and space between the workers and increase the opportunities to support not only traffic controllers or train drivers, but an efficient collaboration between these two central roles. This is something future research should investigate further.

Acknowledgements We would like to thank the traffic controllers and train drivers who so generously participated in this study and provided us unhindered access to their everyday work activities. We would also like to acknowledge our financial support from the Swedish Transport Administration.

Open Access This article is distributed under the terms of the Creative Commons Attribution 4.0 International License (http://creativeco mmons.org/licenses/by/4.0/), which permits unrestricted use, distribution, and reproduction in any medium, provided you give appropriate credit to the original author(s) and the source, provide a link to the Creative Commons license, and indicate if changes were made.

\section{References}

Albrecht T (2013) Human factor challenges in the development of a driver advisory system for regional passenger trains. In: Dadashi N, Scott A, Wilson J, Mills R A (eds) Rail human factors: supporting reliability, safety and cost reduction. Taylor \& Francis, London, pp 129-138

Andreasson R, Lindblom J, Thorvald P (2015) Towards an increased degree of usability work in organizations. Proc Manuf 3:5739_ 5746. https://doi.org/10.1016/j.promfg.2015.07.814

Andreasson R, Lindblom J, Thorvald P (2017a) Interruptions in the wild: Portraying the handling of interruptions in manufacturing from a distributed cognition lens. Cognit Technol Work 19(1):85108. https://doi.org/10.1007/s10111-016-0399-6

Andreasson R, Lindblom J, Thorvald P (2017b) Tool use and collaborative work of dock assembly in practice. Special Issue Prod Manuf Res 5(1):164-190. https://doi.org/10.1080/21693277.2017.13748 90

Andreasson R, Jansson AA, Lindblom J (2018) Past and future challenges for railway research and the role of a systems perspective. In: Proceedings of international ergonomics association conference, 26-30 August, Florence

Artman H, Garbis C (1998) Situation awareness as distributed cognition. In: Green TRG, Bannon L, Warren CP, Buckley J (eds) ECCE 9: Proceedings of the 9th European conference on cognitive ergonomics. European Association of Cognitive Ergonomics, Le Chesnay, pp 151-156

Bainbridge L (1983) Ironies of automation. Automatica 19(6):775-779

Balfe N, Wilson JR, Sharples S, Clarke T (2012) Development of design principles for automated systems in transport control. Ergonomics 55(1):37-54

Bannon LJ (1991) From human factors to human actors: the role of psychology and human-computer interaction studies in system design. In: Greenbaum J, Kyng M (eds) Design at work: cooperative design of computer systems. Lawrence Erlbaum Associates, Hillsdale, pp 25-44 
Bannon LJ (2011) "20 years a-growing”: revisiting from human factors to human actors. In: Isomäki H, Pekkola S (eds) Reframing humans in information systems development. Springer, London, pp 181-188

Berndt E, Furniss D, Blandford A (2014) Learning contextual inquiry and distributed cognition: a case study on technology use in anaesthesia. Cognit Technol Work 17(3):1-19. https://doi.org/10.1007/ s10111-014-0314-y

Blandford A, Furniss D (2005) DiCoT: a methodology for applying distributed cognition to the design of team working systems. In: Proceedings of international workshop on design, specification, and verification of interactive systems. Springer, Berlin, pp 26-38. https://doi.org/10.1007/11752707_3

Braun V, Clarke V (2006) Using thematic analysis in psychology. Qual Res Psychol 3(2):77-101. https://doi.org/10.1191/1478088706 qp063oa

Brown JS, Collins A (1989) Situated cognition and the culture of learning. Educ Educ Res 18:32-42. https://doi.org/10.3102/00131 89X018001032

Clancey JW (1997) Situated cognition: on human knowledge and computer representations. Cambridge University Press, New York

Clark A (1997) Being there-putting brain, body and world together again. MIT Press, Cambridge

Corman F, Meng L (2013) A review of online dynamic models and algorithms for railway traffic control. In: 2013 IEEE international conference on intelligent rail transportation proceedings. IEEE, New York, pp 128-133. https://doi.org/10.1109/ICIRT 2013.6696281

Dadashi N, Scott A, Wilson J, Mills R A (eds) (2013) Rail human factors: supporting reliability, safety and cost reduction. CRC Press, Leiden

Decortis F, Noirfalise S, Saudelli B (2000) Activity theory, cognitive ergonomics and distributed cognition: three views of a transport company. Int J Hum Comput Stud 53(1):5-33. https://doi. org/10.1006/ijhc.2000.0378

Dix AJ (2002) Managing the ecology of interaction. In: Proceedings of TAMODIA-first international workshop on task models and user interface design, pp 1-9

Dorrian J, Hussey F, Dawson D (2007a) Train driving efficiency and safety: examining the cost of fatigue. J Sleep Res 16(1):1-11. https ://doi.org/10.1111/j.1365-2869.2007.00563.x

Dorrian J, Roach GD, Fletcher A, Dawson D (2007b) Simulated train driving: fatigue, self-awareness and cognitive disengagement. Appl Ergon 38(2):155-166. https://doi.org/10.1016/j.aperg o.2006.03.006

Dreyfus HL (1992) What computers still can't do-a critique of artificial reason. MIT Press, Cambridge

Endsley MR (1995) Toward a theory of situation awareness in dynamic systems. Hum Factors J Hum Factors Ergon Soc 37(1):32-64. https://doi.org/10.1518/001872095779049543

Engeström Y (2000) Activity theory as a framework for analyzing and redesigning work. Ergonomics 43:960-974. https://doi. org/10.1080/001401300409143

Evans KJ, Terhorst A, Kang BH (2017) From data to decisions: helping crop producers build their actionable knowledge. Crit Rev Plant Sci 36(2):71-88. https://doi.org/10.1080/07352689.2017.1336047

Farrington-Darby T, Wilson JR, Norris BJ, Clarke T (2006) A naturalistic study of railway controllers. Ergonomics 49(12-13):13701394. https://doi.org/10.1080/00140130600613000

Galliers J, Wilson S, Fone J (2007) A method for determining information flow breakdown in clinical systems. Int J Med Inform 76:113-121. https://doi.org/10.1016/j.ijmedinf.2006.05.015

Golightly D, Balfe N, Sharples S, Lowe E (2012) Measuring situation awareness in rail signalling. In: Wilson JR, Mills A, Clarke T, Rajan J, Dadashi N (eds) Rail human factors around the world: impacts on and of people for successful rail operations. CRC Press, Leiden, pp 361-369

Golightly D, Sandblad B, Dadashi N, Andersson A, Tschirner S, Sharples S (2013) A socio-technical comparison of rail traffic control between GB and Sweden. In: Dadashi N, Scott A, Wilson JR, Mills A (eds) Rail human factors: supporting reliability, safety and cost reduction. Taylor \& Francis, London, pp 367-376

Goodwin C, Goodwin MH (1996) Seeing as situated activity. In: Engeström Y, Middleton D (eds) Cognition and communication at work. Cambridge University Press, Cambridge, pp 61-95

Halverson CA (2002) Activity theory and distributed cognition: or what does CSCW need to do with theories? Comput Support Coop Work (CSCW) 11(1):243-267. https://doi.org/10.1023/A:10152 98005381

Hazlehurst B, McMullen CK, Gorman PN (2007) Distributed cognition in the heart room: how situation awareness arises from coordinated communications during cardiac surgery. J Biomed Inform 40(5):539-551. https://doi.org/10.1016/j.jbi.2007.02.001

Heath C, Luff P (1992) Collaboration and control: crisis management and multimedia technology in London underground line control rooms. Comput Support Coop Work 1(1-2):69-94. https://doi. org/10.1007/BF00752451

Heath C, Hindmarsh J, Luff P (1999) Interaction in isolation: the dislocated world of the London underground train driver. Sociology 33(3):555-575

Heath C, Knoblauch H, Luff P (2000) Technology and social interaction: the emergence of workplace studies. Br J Sociol 51(2):299320. https://doi.org/10.1111/j.1468-4446.2000.00299.x

Hollan J, Hutchins E, Kirsh D (2000) Distributed cognition: toward a new foundation for human-computer interaction research. ACM Trans Comput Hum Interact 7(2):174-196. https://doi. org/10.1145/353485.353487

Hollnagel E (2009) The ETTO principle: efficiency-thoroughness trade-off: why things that go right sometimes go wrong. Ashgate Publishing, Ltd, Farnham

Hutchins E (1995a) Cognition in the wild. MIT Press, Cambridge

Hutchins E (1995b) How a cockpit remembers its speed. Cognit Sci 19(3):265-288. https://doi.org/10.1207/s15516709cog1903_1

Jansson A, Olsson E, Kecklund L (2005) Acting or reacting? A cognitive work analysis approach to the train driver task. In: Wilson JR, Norris B, Clarke T, Mills A (eds) Rail human factors: supporting the integrated railway. Ashgate Publishing Limited, Aldershot, pp 40-49

Jansson A, Olsson E, Erlandsson M (2006) Bridging the gap between analysis and design: improving existing driver interfaces with tools from the framework of cognitive work analysis. Cognit Technol Work 8:41-49. https://doi.org/10.1007/s10111-005-0018-4

Kauppi A, Wikström J, Sandblad B, Andersson A (2006) Future train traffic control: control by re-planning. Cognit Technol Work 8:5056. https://doi.org/10.1007/s10111-005-0019-3

Kecklund L, Mowitz A, Dimgard M (2011) Human factors engineering in train cab design - prospects and problems. In: Human modelling in assisted transportation. Springer, Milano, pp 327-333

Kraut RE (2003) Applying social psychology theory to the problems of group work. In: Carroll JM (ed) HCI models, theories, and frameworks: toward a multidisciplinary science. Morgan Kaufmann Publishers, San Francisco, pp 325-356

Lindblom J (2015) Embodied social cognition. Cognitive systems monographs (COSMOS). Springer, Berlin

Lindblom J, Gündert J (2017) Managing mediated interruptions in manufacturing: selected strategies used for coping with cognitive load. In: Hale KS, Stanney KM (eds) Advances in neuroergonomics and cognitive engineering. Springer, Cham, pp 389-403

Lindblom J, Thorvald P (2017) Manufacturing in the wild: viewing human-based assembly through the lens of distributed cognition. 
Prod Manuf Res 5(1):57-80. https://doi.org/10.1080/21693 277.2017.1322540

Liu Z, Nersessian NJ, Stasko JT (2008) Distributed cognition as a theoretical framework for information visualization. IEEE Trans Vis Comput Graph 14(6):1173-1180. https://doi.org/10.1109/ TVCG.2008.121

Luff P, Hindmarsh J, Heath C (2000) Workplace studies-recovering work practice and informing system design. Cambridge University Press, Cambridge

Millot P (2015) Situation awareness: Is the glass half empty or half full? Cognit Technol Work 17(2):169-177. https://doi.org/10.1007/s1011 1-015-0322-6

Mindell DA (2015) Our robots, ourselves: robotics and the myths of autonomy. Viking Adult, New York

Mumaw RJ, Roth EM, Vicente KJ, Burns CM (2000) There is more to monitoring a nuclear power plant than meets the eye. J Hum Factors Ergon Soc 42(1):36-55. https://doi.org/10.1518/0018720007 79656651

Naghiyev A, Sharples S, Carey M, Coplestone A, Ryan B (2014) ERTMS train driving-incab vs. outside: an explorative eye-tracking field study. In: Proceedings of the international conference on ergonomics \& human factors 2014. CRC Press, Southampton

Nardi BA (1996) Studying context: a comparison of activity theory, situation action models, and distributed cognition. In: Nardi BA (ed) Context and consciousness: activity theory and human-computer interaction. MIT press, Cambridge, pp 35-52

Nilsson M, van Laere J, Susi T, Ziemke T (2012) Information fusion in practice: a distributed cognition perspective on the active role of users. Inform Fusion 13(1):60-78. https://doi.org/10.1016/j.inffu s.2011.01.005

Norman DA (1991) Cognitive artifacts. In: Carroll JM(eds) Designing interaction: psychology at the human-computer interface. Cambridge University Press, Cambridge, pp 17-38

Norman DA (1993) Things that make us smart—defending the human attributes in the age of the machine. Addison-Wesley, Reading

Patton MQ (2002) Qualitative research and evaluation methods, 3rd edn. Sage Publications Inc, London

Pretorius A (2012) A systems approach to the assessment of mental workload in a safety critical environment. In: Wilson JR, Mills A, Clarke T, Rajan J, Dadashi N (eds) Rail human factors around the world: impacts on and of people for successful rail operations. CRC Press, Leiden, pp 370-382

Rogers Y (2012) HCI theory: classical, modern, and contemporary. Morgan \& Claypool Publishers, San Rafael

Rogers Y, Ellis J (1994) Distributed cognition: an alternative framework for analysing and explaining collaborative working. J Inf Technol 9(2):119-128. https://doi.org/10.1057/jit.1994.12

Rogers Y, Marshall P (2017) Research in the wild. Morgan \& Claypool Publishers, San Rafael

Salmon PM, Stanton NA, Walker GH, Baber C, Jenkins DP, McMaster R, Young MS (2008) What really is going on? Review of situation awareness models for individuals and teams. Theor Issues Ergon Sci 9(4):297-323. https://doi.org/10.1080/14639220701561775

Sandblad B, Gulliksen J, Åborg C, Biovie I, Persson J, Göransson B, Kavathazopoulos I, Blomkvist S, Cajander $\AA$ (2003) Work environment and computer systems development. Behav Inf Technol 22(6):375-387. https://doi.org/10.1080/01449290310001624356

Savioja P, Liinasuo M, Koskinen H (2014) User experience: does it matter in complex systems? Cognit Technol Work 16(4):429-449. https:// doi.org/10.1007/s10111-013-0271-x

Sellberg C, Lindblom J (2014) Comparing methods for workplace studies: a theoretical and empirical analysis. Cognit Technol Work 16(4):467-486. https://doi.org/10.1007/s10111-014-0273-3

Shanahan P, Gregory D, Lowe E (2012) Signaller workload exploration and assessment tool (SWEAT). In: Wilson JR, Mills A, Clarke T, Rajan J, Dadashi N (eds) Rail human factors around the world: impacts on and of people for successful rail operations. CRC Press, Leiden, pp 434-444

Simon HA (1981) The sciences of the artificial, 2nd edn. MIT Press, New York

SJ (2018) SJ på 2 minuter (in Swedish). https://www.sj.se/sv/om/om-sj. html. Accessed 4 Apr 2018

Suchman LA (1987) Plans and situated actions: the problem of humanmachine communication. Cambridge University Press, Cambridge

Susi T (2006) The puzzle of social activity - the significance of tools in cognition and cooperation. Dissertation, University of Linköping, Sweden

Szymanski MH, Whalen J (2011) Work practice analysis at Xerox. In: Szymanski MH, Whalen J (eds) Making work visible. Cambridge University Press, Cambridge, pp 1-17

Trafikverket (2015) Trafikledning styr all järnvägstrafik (in Swedish). https://www.trafikverket.se/resa-och-trafik/underhall-av-vag-ochjarnvag/Sa-skoter-vi-jarnvagar/Jarnvagens-utmaningar/Trafikledn ing-styr-all-jarnvagstrafik/. Accessed 4 Apr 2018

Trafikverket (2016) 4000 tåg per dag i tågtidtabellen (in Swedish). https:// www.trafikverket.se/om-oss/nyheter/Nationellt/2016-09/4-000-tagper-dag-i-tagtidtabellen/. Accessed 4 Apr 2018

Tschirner S, Andersson A, Sandblad B (2013) Designing train driver advisory systems for situation awareness. In: Dadashi N, Scott A, Wilson J, Mills R A (eds) Rail Human Factors: Supporting reliability, safety and cost reduction. Taylor \& Francis, London, pp 150-159

Williams RF (2006) Using cognitive ethnography to study instruction. In: Barab SA, Hay KE, Hickey DT (eds) Proceedings of the 7th international conference of the learning sciences, vol 2. Lawrence Erlbaum Associates, Mahwah, pp 838-844

Wilson JR (2000) Fundamentals of ergonomics in theory and practice. Appl Ergon 31(6):557-567. https://doi.org/10.1016/S0003 $-6870(00) 00034-X$

Wilson JR (2014) Fundamentals of systems ergonomics/human factors. Appl Ergon 45(1):5-13. https://doi.org/10.1016/j.apergo.2013.03. 021

Wilson JR, Norris B (2005) Special issue on rail human factors. Appl Ergon 36(6):647-648. https://doi.org/10.1016/j.apergo.2005.08.002

Wilson JR, Norris BJ (2006) Human factors in support of a successful railway: a review. Cognit Technol Work 8(1):4-14. https://doi. org/10.1007/s10111-005-0016-6

Wilson JR, Jackson S, Nichols S (2003) Cognitive work investigation and design in practice: the influence of social context and social work artefacts. In: Hollnagel E (ed) Cognitive task design. Erlbaum, Mahwah, pp 83-98

Wilson JR, Farrington-Darby T, Cox G, Bye R, Hockey GRJ (2007a) The railway as a socio-technical system: human factors at the heart of successful rail engineering. In: Proceedings of the Institution of Mechanical Engineers, Part F [J Rail Rapid Transit 221(1):101115]. https://doi.org/10.1243/09544097JRRT78

Wilson JR, Mills A, Clarke T, Norris B (2007b) Introduction. In: Wilson JR, Norris B, Clarke T, Mills A (eds) People and rail systems: human factors at the heart of the railway. Ashgate Publishing Limited., Hampshire, pp 1-7

Wilson JR, Mills A, Clarke T, Rajan J, Dadashi N (eds) (2012) Rail human factors around the world: impacts on and of people for successful rail operations. CRC Press, Leiden

Wolcott H (2009) Writing up qualitative research, 2nd edn. Sage Publications Inc., California

Woods DD, Branlat M (2010) Hollnagel's test: being 'in control' of highly interdependent multi-layered networked systems. Cognit Technol Work 12(2):95-101. https://doi.org/10.1007/s10111-010-0144-5

Wright PC, Fields RE, Harrison MD (2000) Analyzing human- computer interaction as distributed cognition: the resources model. Hum Comput Interact 15(1):1-41. https://doi.org/10.1207/S15327051H CI1501 01 
Yang L, Lidén T, Leander P (2013) Achieving energy-efficiency and on-time performance with driver advisory systems. In: 2013 IEEE international conference on intelligent rail transportation (ICIRT), pp 13-18. https://doi.org/10.1109/ICIRT.2013.6696260 